\title{
Choosing Physical, Physicochemical and Chemical Methods of Pre-Treating Lignocellulosic Wastes to Repurpose into Solid Fuels
}

\author{
Martin J. Taylor ${ }^{1,2}{ }^{(}$, , Hassan A. Alabdrabalameer ${ }^{1,2}$ and Vasiliki Skoulou ${ }^{1,2, *(\mathbb{D}}$ \\ 1 Energy and Environment Institute, University of Hull, Cottingham Road, Kingston upon Hull HU6 7RX, UK \\ 2 B3 Challenge Group, Department of Chemical Engineering, University of Hull, Cottingham Road, \\ Hull HU6 7RX, UK \\ * Correspondence: V.Skoulou@hull.ac.uk; Tel: +44-1482-465116
}

Received: 2 June 2019; Accepted: 26 June 2019; Published: 30 June 2019

check for updates

\begin{abstract}
Various methods of physical, chemical and combined physicochemical pre-treatments for lignocellulosic biomass waste valorisation to value-added feedstock/solid fuels for downstream processes in chemical industries have been reviewed. The relevant literature was scrutinized for lignocellulosic waste applicability in advanced thermochemical treatments for either energy or liquid fuels. By altering the overall naturally occurring bio-polymeric matrix of lignocellulosic biomass waste, individual components such as cellulose, hemicellulose and lignin can be accessed for numerous downstream processes such as pyrolysis, gasification and catalytic upgrading to value-added products such as low carbon energy. Assessing the appropriate lignocellulosic pre-treatment technology is critical to suit the downstream process of both small- and large-scale operations. The cost to operate the process (temperature, pressure or energy constraints), the physical and chemical structure of the feedstock after pre-treatment (decomposition/degradation, removal of inorganic components or organic solubilization) or the ability to scale up the pre-treating process must be considered so that the true value in the use of bio-renewable waste can be revealed.
\end{abstract}

Keywords: biomass waste; pyrolysis; gasification; physical; physicochemical; chemical; pre-treatment; bio-energy; upgrade

\section{Introduction}

More than ever, there is a drive to accommodate sustainability in the energy generation and chemical production sectors. The scope of this work encompasses utilising or upgrading bio-renewable waste to feedstock materials for the wider energy generation sector. The projected endpoint is to replace or gradually phase out the use of conventional fossil fuel and first-generation biomass-based alternatives with second-generation biomass feedstocks such as lignocellulosic waste which do not compete with food and feed industry [1-3]. However, the true consumption of such feedstock has appeared to remain constant. In 2009 , from the total $10 \%$ of the global primary energy consumption of all kinds of bioenergy, $\sim 80 \%$ of this value was generated from all kinds of biomass waste $[4,5]$. In 2013, the value attributed to energy generated from biomass waste was reduced to $9 \%$ as there has been a drive to advance other technologies [6]. Examples of biomass waste materials are wood, agricultural and/or food fraction of the municipal solid waste, the so called lignocellulosic waste which still remain unexploited [1,2,7,8], i.e., tree branches [9] and other agricultural crops residues [10,11]. On the other hand, first-generation feedstocks (seeds) have been widely investigated and used for liquid biofuel production. Lignocellulosic waste is an example of a very common carbon-rich material that has the potential to generate low carbon energy via thermochemical routes either/or be converted 
into high added value chemicals via downstream thermochemical processing such as pyrolysis and gasification [12]. The literature has a rich array of evidence that this type of waste stream can be used for various methods of digestion to form liquid fuels such as ethanol [13]. This is a favourable type of biomass waste due to its relatively high abundance and overall sustainable nature [7]. Aspects such as the inherent moisture and oxygen content, as well as a relatively low calorific value and high volatile content means that various modifications to add value to waste, otherwise known as pre-treatments, are required to better utilise lignocellulosic biomass waste [1]. However, the composition and structure of the feedstock materials are often complex and contain many polymeric chains. These materials, therefore, require pre-treatment before they can be used as a 'drop in' fuel/chemical platform molecules or for bioenergy production via thermochemical transformation or advanced thermal processing routes $[8,14-16]$. The term 'drop in' fuel denotes a molecule that is synthetically made and has the potential to be used in place of existing fuel-based hydrocarbons [17]. A 'drop in' waste-based material can also be used as a chemical intermediate which could be upgraded into an entirely new feedstock [18]. However, such value-added molecules such as furfural, levulinic acid, glycerol and 5-hydroxymethylfurfural, as well as various other oxygenates and hydrocarbons are highly sought after molecules that can be separated from bio-oil residues that are generated by pyrolysis (fast and slow) and in residues generated after gasification [19-23]. The homogenous liquid generated by flash degradation of cellulose, hemicellulose and lignin generates a rich liquor of molecules that can be separated and upgraded further to generate carbon fibres, resins, polymers and commodity chemicals [24] or this waste-derived oil can be used under gasification conditions and be converted to a mixture of gases (syngas) containing primarily $\mathrm{H}_{2}$ and $\mathrm{CO}$, which have a calorific value and can be used for energy production [21,25]. Enhancing these two thermochemical processes further requires the use of a solid heterogeneous catalyst. This is where a metal-containing or metal-free material can increase product selectivity or alter the thermally driven reaction of waste materials $[21,26]$. Optimising the pre-treatment process for a specific waste material will enhance its usability and practicality for downstream operations. The efficiency of a bio-refinery is often hampered by the crystallinity of cellulose and its troublesome surrounding matrix (hemicellulose and lignin) [27,28]. To overcome this, if the cellulose is the desired component, the pre-treatment process could involve general depolymerisation, matrix weakening, reducing cellulose crystallinity, component degradation (breakdown of hemicellulose or lignin) or solubilisation (transferring a component into the liquid phase), whereas for thermochemical processing, catalytic or non-catalytic, increasing the active surface area of the waste material, weakening the superstructure of the waste without compromising or degrading any of the components and reducing the thermal/thermochemical stability of the material is important.

Various pre-treatment technologies often operate in a similar fashion and can generate the same outcome, facilitate a structural alteration to lignocellulose. This is where various aspects of the material are degraded and hemicellulose and lignin fibres can be broken down [8,29]. The structure of cellulose is simplified in Figure 1A. This is where a monomer fragment is presented, and an individual glucose molecule is highlighted in a red box (Figure 1B). Due to the extensive hydrogen bonding and glycosidic linkages, it would be very difficult to construct a true representation of the cellulosic structure; especially as the true size is dependent on the parent material. Lignin, on the other hand does not contain the same sugar structure as the glucose in cellulose [12]. It is, however, a covalently cross-linked macromolecule with a rigid structure containing alkyl aryl ether units which generate $\beta$-O-4 linkages $[29,30]$. There are various other units present in the different lignin moieties but to a lesser extent $[29,31]$. Various research groups have managed to deduce a simplified structure, this has been broadly modified in Figure $1 \mathrm{C}$ to show the variable functional groups [32,33]. It has been suggested that lignin is constructed from three different hydroxycinnamyl alcohols; paracoumaryl alcohol, coniferyl alcohol and sinapyl alcohol [30,34]. A representation of the structure of these molecules is shown in Figure 1D, again, for visualisation this has been simplified to demonstrate the interchangeable functional groups. Finally, hemicellulose, as the name would suggest is very 
similar to cellulose, this is a misconception. Cellulose is often depicted as linear chains of glucose units (Figure 1A,B), whereas hemicellulose contains a structure generated from a variation of pyranose-based polymers such as xylans, mannans and glucans $[34,35]$. The hemicellulose backbone also contains monosaccharides and various other molecules to augment the overall polymer. One such sugar-based molecule, xylose, is a monomer for xylan a heteropolysaccharide (Figure 1E). This specific molecule is a pre-requisite platform for many furan-based compounds present in bio-oil $[22,23,36]$. Xylan also contains molecules such as arabinose, glucuronic acid and acetic acid as well as various other molecules. Glucomannan on the other hand is a culmination of sugar molecules such as mannose and glucose. The composition of hemicellulose is also dependant on the biomass material; an example of this is that xylans are normally found in non-woody biomass, whereas glucomannans are generally found in softwoods [35].

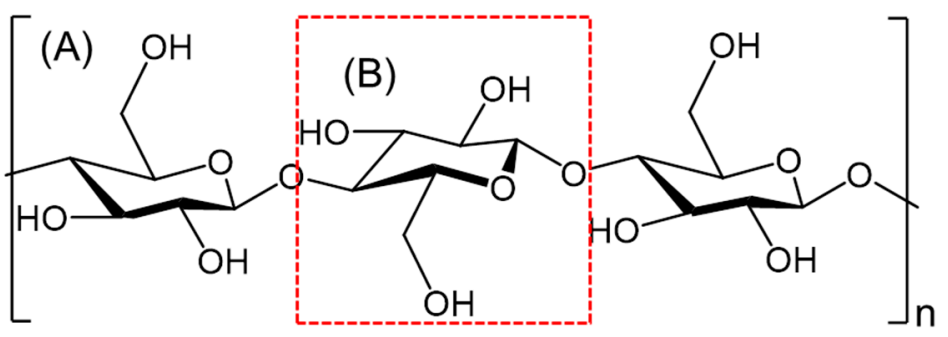<smiles>[R]Oc1ccc(C(O)C(CO)Oc2cccc([R])c2)cc1</smiles>

Figure 1. A general representation of molecules present in lignocellulosic biomass waste such as (D) cellulose section, (A) glucose monomer, (B) lignin monomer representation [33], (C) a simplified structure of an alcohol that constructs lignin [34,35] and (E) xylose, a monomer found in xylan, a component of hemicellulose (non-woody feedstock).

This review will focus on the physical (ball, disc, hammer and jet milling, as well as extrusion), chemical (ozonolysis, acid, base and ionic liquid) and a combination of physicochemical (pressure-induced explosions and interaction with media such as steam, $\mathrm{CO}_{2}$ and ammonia, as well as liquid hot water, microwave irradiation, ultrasound and wet oxidation) pre-treatment methods currently exploited to generate value-added products and energy. Additionally, various emerging pre-treatment technologies that have not yet entered large-scale operation such as pulsed electric field, electron beam and gamma irradiation is included in this work.

\section{Physical Methods of Lignocellulosic Waste Pre-Treatment}

Physically pre-treating biomass wastes left behind from the liquid biofuels production sector (i.e., seeds cake and energy crop stalks) often includes undergoing mechanical or manual processing. This is where the crystallinity of the cellulosic structure can be decreased [37]. This subsequently leads to a variation in the particle size of the waste to be upgraded as feedstock material, as well as increasing the available surface area $[2,3]$. The resulting fine powder can be sectioned off by sieving techniques to 
isolate a specific size, technologies of this type are quite energy intensive. Often, the pre-treatment of biomass waste contributes to $>20 \%$ of the overall production operation cost [38]. This means that an appropriate process much be applied to reap the full benefit of the waste material to be upgraded by this method [39]. Methods of physical pre-treatment covered in this review are drying and mechanical size reduction techniques such as milling and extrusion. There are numerous variations of the base methods described and these will be covered in more detail below. Some of the methods mentioned in the subsequent sections are depicted in Figures 2 and 3.

\subsection{Drying}

Although not often referred to as a method of pre-treatment in the overall literature, drying or dehydrating a feedstock material is a pre-requisite process that can have stark effects on the value of the waste material, especially for thermochemical downstream usability. Typically, the inherent moisture content of lignocellulosic biomass waste is high. Therefore, drying techniques are a minimum necessary requirement for feedstock preparation prior to other pre-treatment technologies. Methods of drying lignocellulosic biomass range from air drying (ambient atmosphere), direct oven drying, convection oven drying (fan assisted) and freeze drying (vacuum sublimation) [40-42]. It has previously been indicated that drying post chemical pre-treatment in ammonium hydroxide will cause the cellulose component to recrystallize [43]. It has also been found that amorphous cellulose can slightly re-crystallise or regenerate after treatment in water, followed by air drying [41]. Whereas oven drying has been found to decrease pore size for some feedstock materials, drying techniques are often used to lower the overall moisture content of the waste material to below $20 \mathrm{wt} \%$ [44]. From the list of physical pre-treatment methods mentioned, due to varying levels of moisture, before/post pre-treatment, this process can often be found to be the most energy demanding; in some cases, this has been found to increase the overall cost of the upgrading process by $3 \%[44,45]$. Whereas for materials that have been dried prior to pre-treatment, it has been found that there is an overall reduction in expenditure by $\sim 2 \%$ [45]. Lignocellulosic waste materials are often hygroscopic by nature, the general moisture content has been found to range between 15 and $60 \mathrm{wt} \%$ [8]. The removal of water content is imperative for improving combustion efficiency and overall calorific value [46]. This means that the temperature required will be reduced dependant on the level of moisture, where oven drying can occur between 45 and $105^{\circ} \mathrm{C}$ [42]. The level of drying is also dependant on whether the feedstock is woody or herbaceous, this leads to a variable inherent moisture content. Examples of non-woody or herbaceous biomass are agricultural wastes such as; straw, grasses and crop stubble $[14,47]$. These residues have been found to contain $>10 \mathrm{wt} \%$ more moisture than wood-based materials. In cases such as wood pellets and wheat straw, the moisture content is almost doubled, and the values are $4.9 \mathrm{wt} \%$ and $8.5 \mathrm{wt} \%$, respectively [14,46]. This means that a greater level of drying is required before these feedstocks can be employed in thermochemical processing for either energy or fuels and carbonaceous materials production. However, if the moisture content exceeds $60 \mathrm{wt} \%$, the required input energy for dehydration exceeds the output energy of the material by over $10 \mathrm{wt} \%$ [46].

\subsection{Particle Size Reduction Techniques}

Determining the optimum feedstock particle size can be a difficult process due to the fibrous properties of the lignocellulosic biomass waste [44]. A large particle size can contribute to a reduced conversion efficiency due to reduced heat and mass transfer rates when generating heat energy in a boiler, therefore, reducing the particle size of the residues will increase the efficiency of releasing as much as possible of the calorific content as useful energy $[47,48]$. In addition, the specific surface area and porosity of the feedstocks have an impact on bio-ethanol production during the enzymatic hydrolysis of biomass wastes [49]. There are a number of different physical/mechanical techniques that can be applied to reduce the crystallinity of cellulose, which results in increasing the available surface area for thermal contact and thus increased heat and mass transfer rates, as well as porosity of the feedstock material and particulate size $[7,27,48-51]$. The first of these methods to be explored 
is generally the primary method used for large-scale lignocellulosic biomass waste valorisation, i.e., milling [3].

\subsubsection{Ball Milling (Wet and Dry)}

This is a high intensity method of milling where the centripetal forces of the metallic balls exert a shearing force on the material that reduces the net crystallinity [27,50]. This method of processing is fit for purpose for both batch and continuous scales for exploiting further energy production (modifying first-generation feedstocks after liquid biofuel production) or for initial pre-treatments of second-generation waste materials. The size of the vessel (grinding jar) can be varied, as well as the number of metallic spheres used [50]. This is often distinguished by the different nomenclature used such as ball mill or a planetary ball mill (Figure 2A) [52]. However, due to the high energy requirements for this process, it is often seen as an expensive method of pre-treatment and not sustainable for long term use (long processing times) [53]. In other cases, ball milling is seen as an environmentally friendly (low energy consumption) method of pre-treatment that has proven to be versatile in a number of conditions [54]. Such conditions involve the comparative use of solvent and solvent free (dry) conditions to disrupt hydrogen bonded networks within the cellulose superstructure [54].
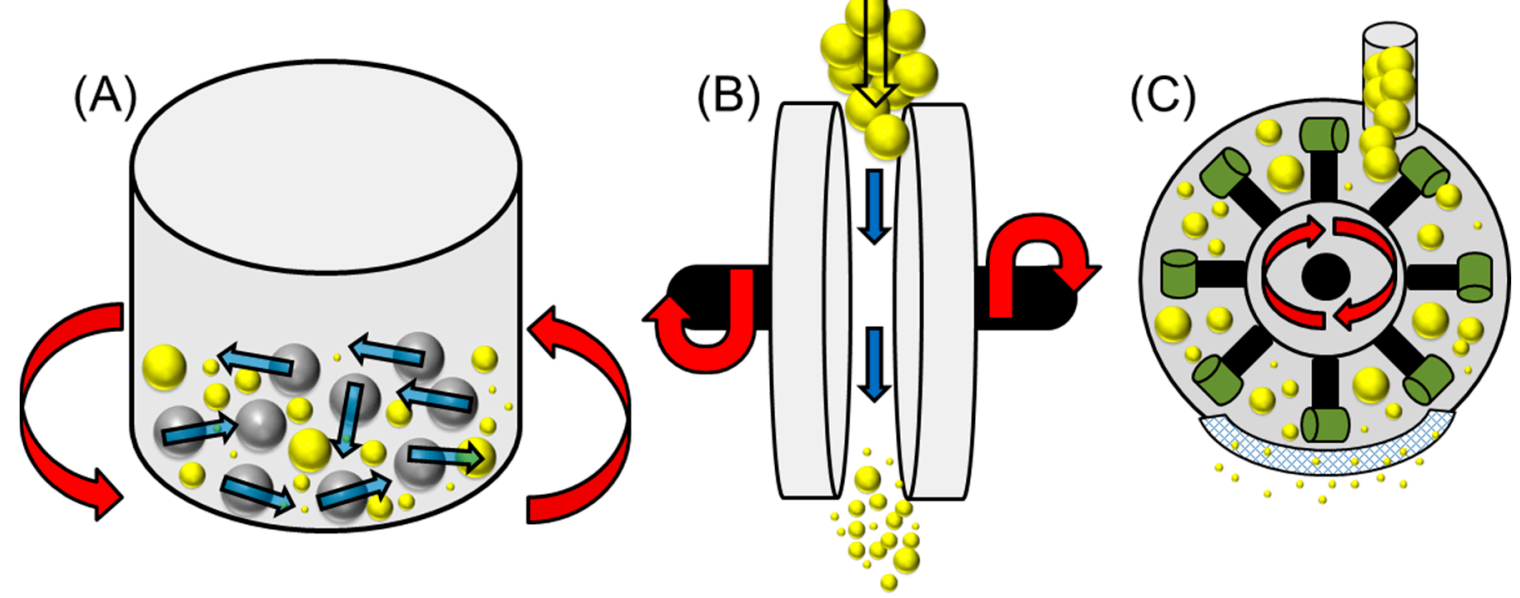

Figure 2. A general schematic for an opposed jet milling (particle-particle collision) process and subsequent particle sizing. ( : lignocellulosic biomass waste particles).

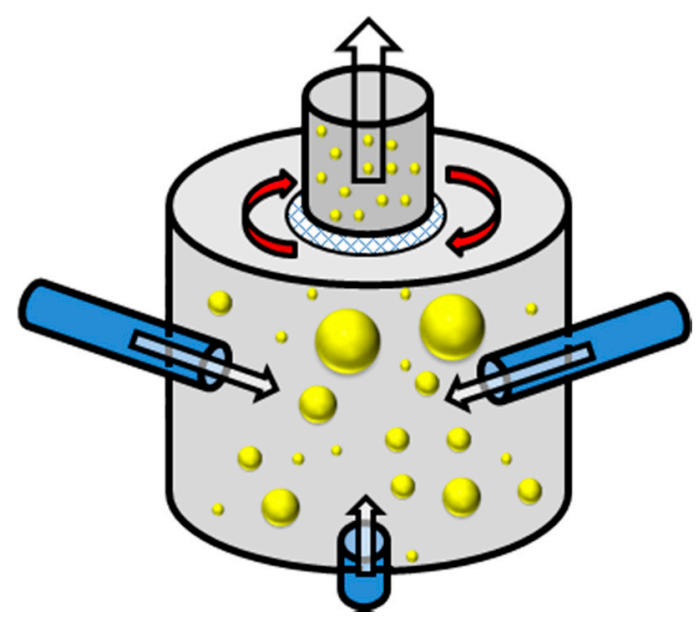

Figure 3. A modified diagram (from reference 45) depicting various mechanical pre-treatment techniques: (A) Ball milling (grey spheres indicate metallic balls), (B) Disc milling and (C) Hammer milling (with blunt hammers) [55]. ( : lignocellulosic biomass waste particles). 
This form of milling begins to bridge the gap between physical and physicochemical pre-treatment processes, where various research groups have begun to investigate the coupling of acid treatment and ball milling for the breakdown of lignin in the substrate [56-58]. Using a relatively low acid concentration at room temperature in tandem with ball milling causes the porous material to undergo swelling and subsequent destructive action occurs. This process route has been considered less harsh than conventional acid hydrolysis which uses a greater acid concentration (discussed in greater detail further into the review) [56-58]. Additionally, the operation of swelling and milling temperature is carried out at room temperature, thus requiring less energy to treat the lignocellulosic material than a conventional milling practice $[55,58]$.

\subsubsection{Disc Milling (Wet and Dry)}

Figure 2B shows the schematic design for a disc mill (also known as a double disc attrition mill [59]). This is where two serrated plates (the surface of the disc can be designed to suit the purpose) are positioned within close proximity to one and other. The waste feedstock is passed through the system and the rotating discs will apply a shear force at high speed to the particles under a high pressure $[48,60]$. Some designs use a pair of rotating discs or a configuration of a static accompanied by a rotating unit [55]. As Figure 2B shows, this is a continuous process and can be added to throughout its operation. This being said, out of all physical pre-treatment methods, disc milling requires a vast amount of energy with a specific energy consumption of $200-400 \mathrm{kWh} / \mathrm{t}$, to produce a particle size of approximately $2 \mathrm{~mm}[59,61]$. The design of the disc itself specifies the operation of the mill and the overall mechanical refining process. This has been discussed in greater detail by Corbett and co-workers. They analysed the three combined operations of the disc mill: fibre cutting, external fibrillation and internal delamination $[62,63]$. The disc design/surface profile, the consistency of the feedstock properties (mainly moisture content) and positioning of the discs can have a stark impact on the process output $[63,64]$. Similarly with ball milling, the disc milling process has been explored in both dry and wet milling conditions where the feedstock is pre-softened or swollen [60,61,63-65]. It has been shown that combining the pre-treatment protocol by hydrating the waste material with steam, mild acidification or with ozone-infused water (method of chemical pre-treatment discussed later) $[63,64]$ prior to disc milling could be an option for minimising the energy demand (mentioned previously) and yielding a higher glucose return for fermentation reactions [65]. For thermochemical downstream processes, the method of wet disc milling has also been found to be more energy efficient for moist poplar chips. However, there can be a large variation in particle size for this method of size reduction as found in other downstream processes [66].

\subsubsection{Hammer Milling}

Unlike other physical pre-treatment methods mentioned thus far, the hammer mill (Figure 2C) is extremely variable and seen as a coarse method of milling [61,66]. Not only can the number, shape, rotation speed and hammer design (blunt/sharp) be altered but the sizing grid at the base of the unit can be tailored to a specific particle size [39,48,67-69]. The design of this system includes a series of hammers attached to a rotor. As the rotor spins, the hammers will collide with the feedstock that is fed continuously. On each pass the particle size should decrease and eventually fall through the sizing grid. Dependant on the physical properties of the biomass waste, either a blunt or sharpened hammer configuration can be used [39]. However, one of the draw backs to hammer milling is the size distribution of pulverised waste material, this can often mean that a second method of physical milling is required [61]. For this milling procedure, waste particle size variation is a concern; so to prevent blockages, the sizing screens are angled (circular, as in Figure $2 \mathrm{C}$ or trapezoid) to prevent sediment build-up [69]. This means that as the impaction process takes place, small particles pass through the grid but those of slightly larger size can also do the same. Additionally, hammer milling is seen as the second most energy intensive method of physical refining after disc milling $[59,61,66]$. This means that the costs required to operate large-scale hammer mills could prove to be very expensive. Also unlike 
the other methods mentioned, due to material compaction, the feedstock is extensively dried for this process. Therefore, wet hammer milling is not an option [66].

\subsubsection{Jet Milling}

While coarse milling (hammer mill) and semi fine milling (ball milling) have been mentioned. There is a method of 'ultra'-fine milling that uses compressed gases to force single impactions (impaction on the side of the milling chamber) or particle-particle collisions (double collisions). This is known as jet milling [66,70]. The gases usually used for this process are compressed air, nitrogen (inert gas) or steam (a method of swelling the biomass waste before impaction) [66]. Nominal pressures for this practice are usually approximately $5 \mathrm{bar}$, as the gases are introduced, a cyclonic effect is generated [71]. Figure 3 depicts a schematic for an opposed jet mill. This is where there are numerous gas injection apertures which force the biomass waste particles to collide with one and other in the centre of the vessel. This type of jet mill has been seen as the most effective for fine powder production [72]. However, there are other jet milling designs such as the spiral and oval chambers-these are also considered to be attrition type mills $[66,70,72]$. These designs can accommodate a single gas outlet that will force particles to impact against the vessel itself. Once the waste particles are of relevant size, they can pass through a rotating sizing grid, allowing the particulates to pass on to the next step of the process. [70] The operational speed of the rotary sieve is between 3000 and 20,000 rpm which can allow particles of $\sim 20 \mu \mathrm{m}$ through [70,71]. This method of milling must first receive a pre-ground feedstock so that it can be effective, this is often received from either a ball or hammer mill [71]. The relative energy consumption for this technique is variable between designs, although producing a finer powder, the opposite jet mill has been found to use more energy than its spiral equivalent [70].

\subsection{Reactive Extrusion Refinement}

Once the optimum particle size has been obtained, a typical follow on process is extrusion refinement [61]. This is where a continuous feed of material is driven through either a single or dual screw threads that run the length of a stationary chamber (Archimedean screw), this can have several sections which provide a range of heating environments [61,73-76]. During this time, the material can pass through different reactive chemical and thermochemical environments [73]. Additionally, if there are a number of screws present, the threads can either rotate in the same direction (drive the feed in one direction) or counter to one and other (further enhanced grinding effect) [74]. The screw driven extrusion process is highly customizable as a physical pre-treatment process. However, this technique could also be considered as a physicochemical process due to its additional functionalities. Not only is the system optimizable due to screw thread drive speed (typically 25-200 rpm), thread dimension, variable barrel temperature (typically $25-200^{\circ} \mathrm{C}$ ) but it also has the capacity to add acid, alkali and water treatments for swelling, similar to that mentioned for ball and disc milling $[8,73,75,76]$. By varying the design of the thread itself, the feedstock can be mixed, transported or reversed (held temporarily) [61,73]. Operating a variable direction thread means that the biomass waste substrate can undergo densification. This is where the biomass particles are compacted, increasing their bulk density [66] so that they can be more effective as a solid biofuel, i.e., valorised as an alternative fuel source for residential heating [77]. Extrusion is one of a few methods of densifying waste material —others are briquetting or pelletizing. As the feedstock progresses along the screw, it enters a number of chambers that can have variable temperatures. Here, the material can either be dried, absorb moisture (water containing section) or undergo thermal expansion. This is usually followed by a pressure inducing section of thread; this allows the particles to undergo various intensities of shear, stress or even densification [66,73]. As the compacted material exits the high pressure segments it is able to expand, causing further stress/strain action [14]. This method of pre-treatment has also been proved to be beneficial for the down-stream process of anaerobic digestion, specifically producing methane [78]. Also, extrusion of biomass waste can bridge the physical and biological pre-treatment methods. Although biological pre-treatments are not a topic covered in this review, extrusion refinement can also utilise bio-catalytic enzymatic 
hydrolysis by adding a series of enzymes during the drive process [79,80]. A combination of the two methods, extrusion and enzymatic hydrolysis, have yielded strong results for 'bio-extrusion' operation due to the physical pre-treatment technique generating an increased surface area, greater pore size/volume and a reduction to cellulose crystallinity [73,79]. Naturally, due to the variable heating zones and working parts, this method of pre-treatment requires a high capital investment and has a large energy consumption [55].

\section{Physicochemical Methods of Lignocellulosic Waste Pre-Treatment}

Methods of pre-treatment that operate in a hybrid approach, affecting the physical parameters (mentioned previously) as well as their chemical bonding (bond cleavage) and intermolecular interactions, are called physicochemical techniques [81]. This is where aspects such as temperature or pressure are used in tandem with a chemical process. These techniques are often intense and can break down the lignocellulosic waste by using methods such as; steam and $\mathrm{CO}_{2}$ explosion, ammonia fibre explosion, (a general schematic demonstrating the effect of rapid decompression on a porous network is shown in Figure 4, this diagram does not contain various side reactions that can occur when using $\mathrm{CO}_{2}$ or ammonia) liquid hot water, microwave irradiation, mechano-acoustic/sono-chemical processing and wet oxidation [81-84].

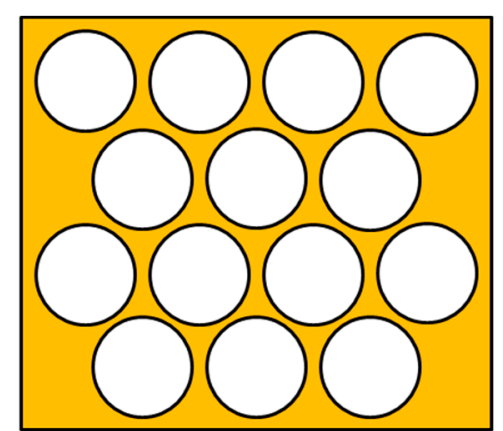

(A) Untreated material

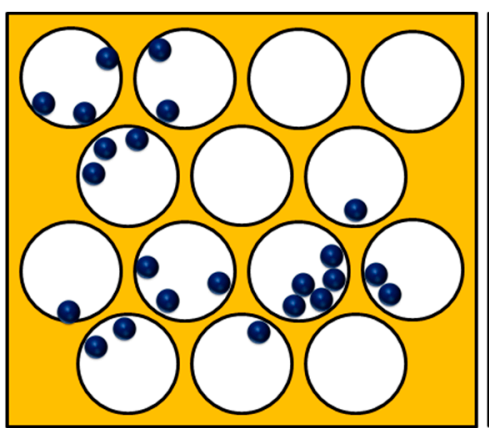

(B) Adsorbent addition

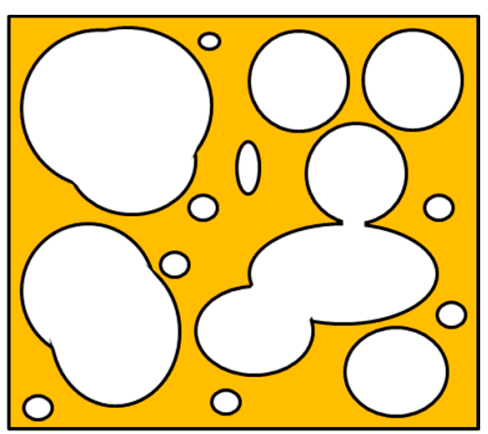

(C) Post explosion

Figure 4. A visual representation of the porous network of lignocellulosic waste and the effect of a pressure-induced explosion pre-treatment. This shows the three stages: (A) unaltered material, (B) material containing adsorbent and, (C) the result of rapid decompression.

\subsection{Pressure-Induced Fibre Explosion}

\subsubsection{Steam $\left(\mathrm{H}_{2} \mathrm{O}\right)$ Explosion}

The initial pre-treatment technique mentioned in this category and often seen as the most common is steam explosion, also known as auto-hydrolysis $[82,83]$. This is a hydrothermal process that exerts high pressure $\left(0.7-48\right.$ bar) and temperature $\left(160-260^{\circ} \mathrm{C}\right)$ on the substrate $[13,83]$. After a period of time, the system is rapidly depressurised and re-pressurised [82]. This means that steam is forced into the porous network of the fibrous waste and upon decompression will rapidly expand causing an 'explosion' (Figure 4) [13,81,85]. This causes alterations to the chemical structure of the waste to be upgraded by disrupting intermolecular interactions such as the hydrogen bonding in the matrix, leading to hydrolysis of the physical bonds. It also operates a high intensity mechanical shearing force on the particle structure, similar to methods of milling mentioned previously. As a result, explosion-based treatments increase the surface area of the particles of biomass waste, as well as radically altering both the pore size and volume, while decreasing the overall bulk density. This is a very important characteristic which impacts strongly on the logistics (storage-handling and transportation) of the waste materials from the bioenergy/biofuels sector for transformation into solid biofuels (pellets), mentioned previously for downstream utilization in the residential heating sector [77]. This technique is time resolved meaning that the intensity of the so-called explosion can be controlled by changing 
the rate of decompression $[81,85]$. By using this method of pre-treatment, Datar and co-workers were able to generate biogas with a high hydrogen yield from hemicellulose without additional acid treatment [86]. This being said, there has been several reports of $\mathrm{H}_{2} \mathrm{SO}_{4}, \mathrm{CO}_{2}$ (mentioned later) and $\mathrm{SO}_{2}$ being charged to the reactor and acting as a catalyst to improve sugar recovery $[13,83,87]$. Unlike many other pre-treatment processes mentioned thus far, steam explosion is seen as a relatively low energy consuming technique, especially when compared to motor driven mechanical shearing methods [13]. The biggest cost associated with this technology is the pressure equipment.

\subsubsection{Carbon Dioxide $\left(\mathrm{CO}_{2}\right)$ Explosion}

As well as previously being mentioned as a catalyst for the explosion process, full-scale $\mathrm{CO}_{2}$ explosions have been completed in the past [13]. In an identical manner, carbon dioxide is charged to the reactor at a specific pressure. Depending on the scope of the pre-treatment $\mathrm{CO}_{2}$ has been used at pressures between 30 bar (similar to steam-based explosions) and 275 bar (super-critical $\mathrm{CO}_{2}$ ) $[51,88,89]$. Temperatures are slightly milder than steam explosions, operating between 35 and $175^{\circ} \mathrm{C}$ [88-90]. Super-critical $\mathrm{CO}_{2}$ processes are conducted without the addition of mixing during the residence period, whereas for relatively low $\mathrm{CO}_{2}$ pressures, $\mathrm{Cha}$ and co-workers utilised an impeller that mixes the feedstock as it is being heated under pressure [89]. The base of the reactor can be connected to a second evacuated container and the pressure difference between the two vessels operates the decompression activity. Running a reactor in this fashion allows the $\mathrm{CO}_{2}$ to be recycled [89]. The $\mathrm{CO}_{2}$-based explosion method of pre-treatment has been used for lignocellulosic waste hydrolysis processes. It has been found that the decompression explosion induced by $\mathrm{CO}_{2}$ entering the porous networks is beneficial for increasing the available surface area of the waste material [88]. This occurs especially when super-critical $\mathrm{CO}_{2}$ is used as the nature of the reactant has both liquid and gas natures. As a liquid, the $\mathrm{CO}_{2} \mathrm{can}$ enter the feedstock and form carbonic acid, although seen as a weak acid it has been found to conduct hydrolysis $[13,51,84,88]$. To effectively achieve the double-edged sword of acid-induced hydrolysis and 'explosion-based' shear forces, the feedstock material should not be dried as the $\mathrm{CO}_{2}$ gains its acidic attributes when dissolved in water [51,84]. Again, the energy consumption of pressure-induced fibrous explosions is seen as relatively low. However, the initial cost and potential maintenance costs for high pressure equipment, especially when conducting super-critical pre-treatments is very expensive. On an environmental stand point, this is a green method of pre-treatment as the $\mathrm{CO}_{2}$ used is readily recycled, as can the consumed $\mathrm{CO}_{2}$ during downstream thermochemical processing where it can be reactively reclaimed [89]. This being said, operating a carbon dioxide explosion treatment has been found to be not economical when utilising the higher pressures mentioned [82].

\subsubsection{Ammonia Fibre Explosion (AFE)}

Another method of fibrous explosion has been explored using heated liquid ammonia $\left(\mathrm{NH}_{3}\right)$. This pre-treatment technique has been found to increase the surface area of the waste material, decrease the crystallinity of the cellulose component in the waste and break down or alter the structure of lignin [87]. This is a solvent dependant pre-treatment process that utilises a lower operational temperature $\left(60-120^{\circ} \mathrm{C}\right)$ than stream $/ \mathrm{CO}_{2}$ explosions. Additionally, pressure requirements for this pre-treatment have also been found to be lower than those used for low temperature $\mathrm{CO}_{2}$ explosions at 17.2-20.6 bar [84]. Unlike the other pressure-based methods mentioned, the effectiveness of this waste pre-treatment is dependent on residence time before rapid decompression. Also, this technology benefits from a level of moisture in the waste feedstock to be pre-treated in a similar way to $\mathrm{CO}_{2}$ explosion. This method of explosion also conducts the cleavage of ester linkages via ammonolysis and hydrolysis reactions, generating various other side products [91,92]. It has also been found that the porosity of the lignocellulosic biomass waste is increased when using ammonia fibre explosion. This is because there is a partial solubilisation of lignin during the pre-treatment [91]. This means that this method of pre-treatment is more favourable for herbaceous waste (straws) compared to woody biomass (hard wood) waste which often but not exclusively have a lower lignin content [82]. 
However, although the lignin content is often seen as lower, the cross polymer covalent linkages between lignin and cellulosic network in materials such as grass lignins lead to a far higher structural strength and cell wall integrity [93]. Although proven to be a very effective pre-treatment process, there is a large initial overhead cost for the ammonia reagent; this can be overcome by the fact that the chemical can be recycled [82]. This process has also been found to inhibit the activity of enzymes with lignin due to its solubility as mentioned previously. Therefore, this could be a more attractive pre-treatment protocol for thermochemical upgrading, albeit utilising a lower ammonia concentration to limit lignin degradation, unless as mentioned previously, herbaceous waste materials are used due to their generally lower lignin content than wood-based alternative wastes.

\subsection{Liquid Hot Water (LHW) Method}

Hydrothermal processes are attractive due to the low capital cost of the primary reagent, water. This also applies as a physicochemical biomass waste pre-treatment tool as the relative ease of the process can be adapted from at a lab scale to a pilot and industrial scale. Typically, liquid hot water pre-treatments are very similar to steam explosion. However, the process is conducted in the liquid phase at a high temperature range of $160-250{ }^{\circ} \mathrm{C}$. Also, it operates at a far lower pressure ( 5 bar); this means that the overtime reduces chemical and mechanical fatigue for the equipment $[36,51,55,83,84]$. Another process cost can be avoided as compared with other chemical pre-treatments and that is the need to neutralise or wash the pre-treated biomass waste material after the process. This pre-treatment causes hydrolysis of hemicellulose and will also reduce the lignin content while only $4-22 \mathrm{wt} \%$ of the accessible cellulose has been seen to be removed [51,87]. Although not utilising an external protonation source, when operating at the upper temperature stated, the $\mathrm{H}^{+}$content of the water has been found to be over $20 \times$ higher than when at room temperature [55]. This means that the liquid hot water pre-treatment process will act as a double-edged sword, and mild acid hydrolysis can also take place. This pre-treatment is completed without the requirement to rapidly decompress the reactor, but controlling the residence time (15-70 $\mathrm{min})$ instead to better optimise cellulosic content $[36,94]$. Liquid hot water pre-treatments lead to two fractions being made, the first being a liquid component containing solubilised hemicellulose and the second is the solid pre-treated fraction that can be dried and undergo thermochemical transformation for energy and carbonaceous materials production [36].

\subsection{Microwave Irradiation Method of Biomass Waste Pretreatmemt}

By introducing electromagnetic radiation in the form of microwave irradiation, lignocellulosic biomass waste can be heated at the molecular level by dipole rotation [95-98]. By heating the moisture content within the substrate, a swelling effect will occur and cause depolymerisation of the lignin component while at the same time causing a decrease in the crystallinity of cellulose $[95,98]$. The heating process for microwave irritation is the complete opposite compared to conventional heating. This is where heating occurs from the outside-inwards, whereas microwaves heat from the inside-out, as shown in Figure 5 [96]. This can generate hot spots within the polymeric structure and could facilitate an 'explosion' like effect, comparable with steam $/ \mathrm{CO}_{2} / \mathrm{ammonia}$ fibre explosions. This is where inhomogeneous heating can occur in a waste sample, at a different rate to the rest of the material. It has also been assumed that the 'microwave effect' can destabilise the crystalline structure of waste materials, not relatable with thermal effects $[96,97]$. 
(A)

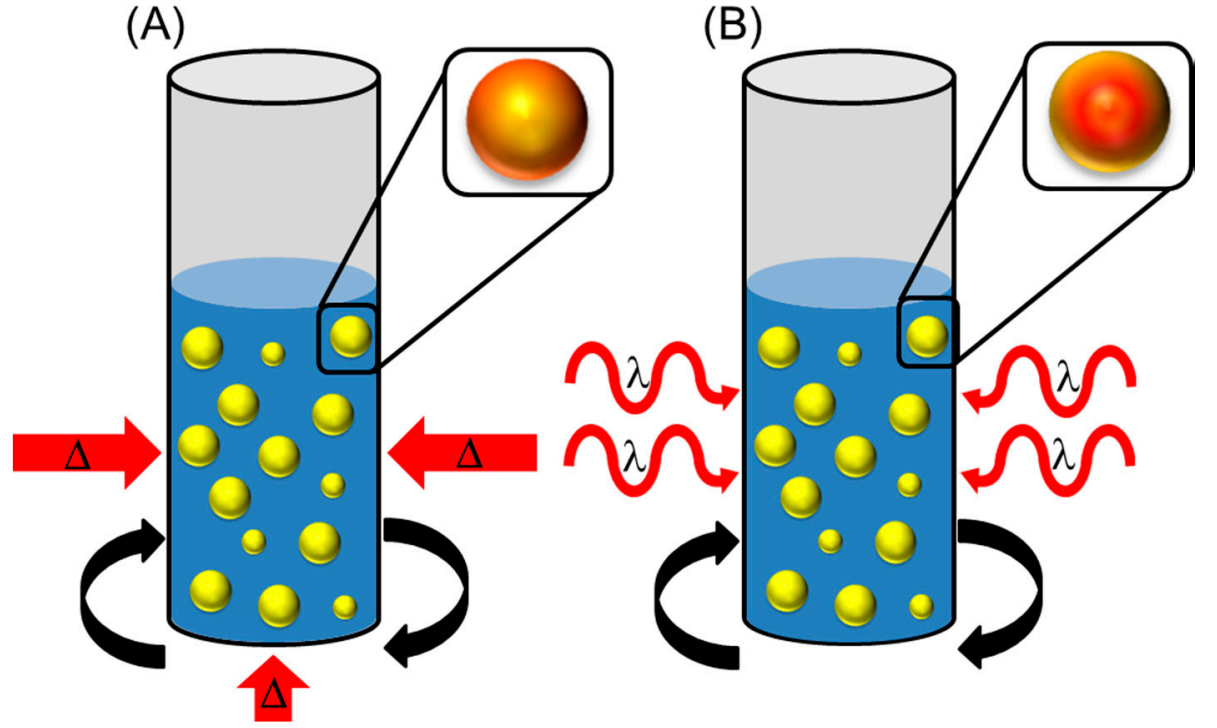

Figure 5. A demonstration of (A) conventional heating versus (B) microwave heating of biomass in a solvent medium. Where : biomass waste particles and, 0 : darker red indicates a warmer region.

However, microwave irradiation as a method of heating is dependent on the dielectric properties of the waste to be upgraded. The pre-treatment of biomass waste in this form takes place similarly to the hydrothermal process mentioned previously. The biomass waste is homogenised into a solvent medium and heat at a specific temperature, residence time and substrate/medium ratio. This means that the material can be 'selectively' heated-the temperature of the specific solvent can be heated and the waste itself not allowed to superheat. There are many differences between available solvents used in the specific process, and that occurs due to their polarity. A polar solvent such as $\mathrm{H}_{2} \mathrm{O}$, alcohols, acetone or acetonitrile, will have a greater ability to be heated as they can absorb the radiation. The opposite of this is non-polar solvents such as alkanes, toluene and dichloromethane, these possess much higher dipole moments meaning less radiation can be absorbed, thus less heating. Recent reports of microwave-induced pre-treatments have been conducted between 130 and $200{ }^{\circ} \mathrm{C}$, over a variable residence time (3-30 $\mathrm{min}$ ) and power input (200-800 W) [96,98-101]. This process on a whole can be seen thus far more energy efficient than a conventional heating method. Not only is the energy conversion caused by the rotating dipole emitting heat energy via conduction to cooler regions of the solid. The hotspots formed by almost instantaneous heating is a far more effective method of causing an 'explosion' within the biomass waste porous network. This in conjunction with a short residence time means that the pre-treatment can potentially be energy and time efficient.

Similarly with other pre-treatment processes, this physicochemical process can be assisted by acidifying the biomass material or by using a base [98,102]. Comparably with other methods of biomass waste pre-treatment, the addition of a base has been found to reduce lignin content, altering the available surface area and generating a larger pore size within the particles [100].

\subsection{Mechanoacoustic and Sonochemical (Ultrasound) Methods}

Ultrasound as a method of biomass waste pre-treatment is where the substrate is immersed in a solvent/medium and irradiated; this causes variations in pressure due to the formation of bubbles/cavities in the medium and, upon their collapse, this results in areas of superheating and high pressure as shown in Figure 6. This method of pre-treatment has been found to enhance physical (mechanoacoustic) and chemical (sonochemical) ultrasound processes over a broad spectrum of frequencies [3,103-105]. The wave is formed by a piezoelectric transducer that vibrates, dependant on the current supplied, the resonance will increase/decrease. The resultant wave can pass through a medium such as water, similarly to microwave irradiation. As the wave passes through the water, 
there are regions formed of both high and low pressure. Areas of lower pressure produce bubbles; these entities are cavities formed between water molecules as they separate. The bubble will undergo a collapse, and this causes an energy conversion that creates an area of superheating. The overall process of pressure differences generates a bubble, leading to the formation of a cavity is shown in Figure 6.

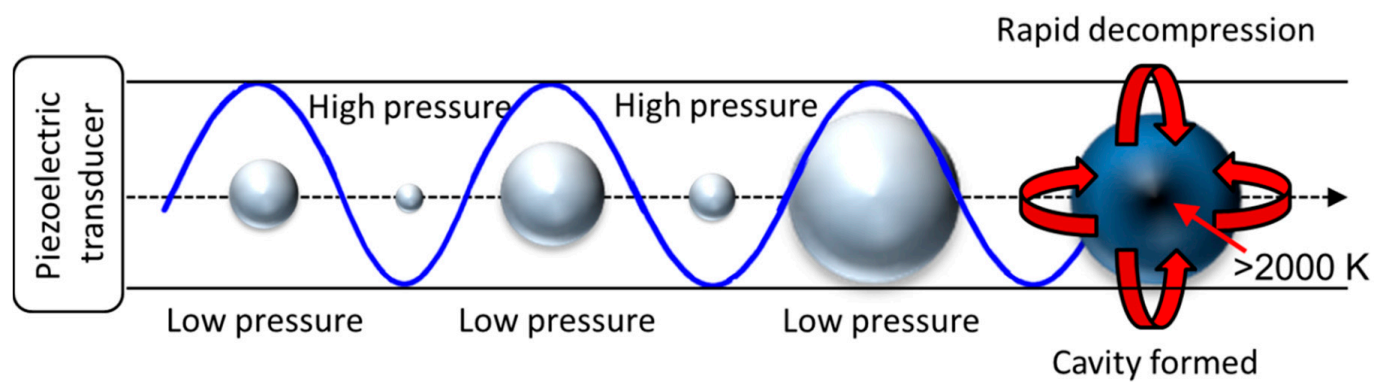

Figure 6. The process of mechano-acoustic pre-treatment, the formation of a bubble (low pressure regions) and eventual collapse (high pressure) forming an area of superheating (red arrow).

This phenomenon is similar to microwave pre-treatment. However, ultrasound technologies have been found to create superheated zones of very high temperature $(>2000 \mathrm{~K})$ and pressure $[103,104]$. Unlike the rapid decompression from the explosion pre-treatment methods mentioned previously, the collapse of a bubble will physically alter the polymerisation of the biomass components by weakening bonds between lignin and the cellulosic network [106]. This is due to the formation of micro jets emitting from the bubble's collapse, these are likened to a shockwave that can travel at high speed through the material $[104,107]$. These reduce the crystallinity of cellulose of the biomass waste and also increase the overall available surface area of the substrate [3,108]. These various structural effects caused by ultrasound make this pre-treatment procedure attractive for further downstream thermochemical treatments, where less energy would be required to decompose the biomass waste material. Sonochemical effects on the other hand occur from the formation of free radicals during the cavity collapse [109]. These can then go on to undergo chemical reactions with molecular side chains that can alter the polymeric structure in tandem with mechano-acoustic alterations mentioned previously [104]. It has also been found that sonication can improve the gaseous products yield during thermochemical transformation, as well as improve the rate of reaction for the production of bio-diesel as compared to conventional approaches after substrate pre-treatment [110]. Additionally, the use of ultrasound technologies has been used to demulsify bio-oils (a product of the thermochemical process of pyrolysis) so that they can be better separated and reformed via catalytic upgrade (oxidation or hydrogenation) [110]. There are two distinct methods of ultrasound pre-treatment, direct and an indirect irradiation. The former involves the submersion of a probe that can direct the waves from a point at a specific frequency and power output [105]. However, due to the severity of the process, probes are generally used in a pulsed action, an example of this was carried out by $\mathrm{Yu}$ and co-workers who operated for $10 \mathrm{sec}$ and rested for $2 \mathrm{sec}$ for a total of $0.5 \mathrm{~h}$ when they pre-treated a herbaceous biomass [111]. The second method is where a sample can be placed in a heated ultrasonic bath, where typical temperatures used have been $25-60^{\circ} \mathrm{C}$. This is where the waves operate in a sweeping action across the unit and will indirectly interact with the sample [107]. For both cases, the formed micro jets have the ability to not just breakdown the molecular structure of the material but can also reduce the overall particle size of the waste material. This mechanical action is likened to other milling techniques mentioned previously, where a smaller particle size can facilitate in a greater surface area for thermochemical transformation. Or has been found to increase glucose yield for enzymatic hydrolysis [105].

\subsection{Wet Oxidation}

Utilising an oxidizing agent in an aqueous environment has been found to be a beneficial method of pre-treatment to breakdown lignocellulose into its constituent parts [112]. Often used as part of a larger pre-treatment process, combined with various milling and explosion techniques (mentioned 
previously), the oxidative process has been found to increase the solubilisation of hemicellulose and breakdown lignin. This is why the process has been referred to as oxidative delignification in the past $[13,82]$. Examples of oxidisers used previously are pressurised gases such as air and oxygen (5-30 bar) or liquid-based peroxides [3,112-114]. Operational temperatures for this process in the presence of an oxygen rich atmosphere have occurred between 120 and $350{ }^{\circ} \mathrm{C}[3,115]$. Residence times are typically between 0.5 and $4 \mathrm{~h}$, whereas hydrogen peroxide-based pre-treatments have occurred at a far milder temperature $\left(30^{\circ} \mathrm{C}\right)$ with a much longer residence time of $\sim 8 \mathrm{~h}[13,115]$. For the pre-treatment of materials such as wheat straw, the solubilization of hemicellulose has been found to be a function of temperature, where the concentration in the solution increased by 3 -fold when increasing the temperature of the process from 150 to $185^{\circ} \mathrm{C}$ [116]. The oxidative mechanism evolves carbon dioxide and water as products where complete oxidation occurs. Additionally, the decomposition of polymeric chains can lead to the formation of low molecular weight carboxylic acids, aldehydes and alcohols upon hydrolysis [117]. Similar methods of free radical interactions are seen in sonochemical pre-treatments (mentioned previously), this can lead to the formation of hydrogen peroxide which is a strong oxidising agent in its own right [115]. Wet oxidation is often coupled with a sacrificial water soluble base, although providing an additional cost to the overall process, and has been found to be beneficial when isolating high cellulose yields from lignocellulosic biomass waste [116].

\section{Chemical Methods of Lignocellulosic Waste Pre-Treatment}

In chemical methods for pre-treating lignocellulosic biomass, the physical structure is not milled and the methods are usually performed in the absence of pressure, across an array of temperatures in the presence of an acidic or alkaline-based environment that can attack the chemical structure of the biomass waste material, often facilitating hydrolysis or delignification reactions. Here, the bonding (covalent) and intermolecular interactions (hydrogen bonding) are weakened causing the polymeric structure to deteriorate [118]. This induces the separation of lignin and hemicellulose components from the cellulosic superstructure. Other options available for this method of pre-treatment are the use of ozone as a strong oxidization agent (Figure 7), organic solvents at high temperatures and ionic liquids. Finally, a pre-treatment protocol is discussed that, unlike many others, operates primarily to reduce inorganic components from the biomass waste substrate, while mildly altering the textural characteristics of the feedstock, this is called leaching (Figure 8).

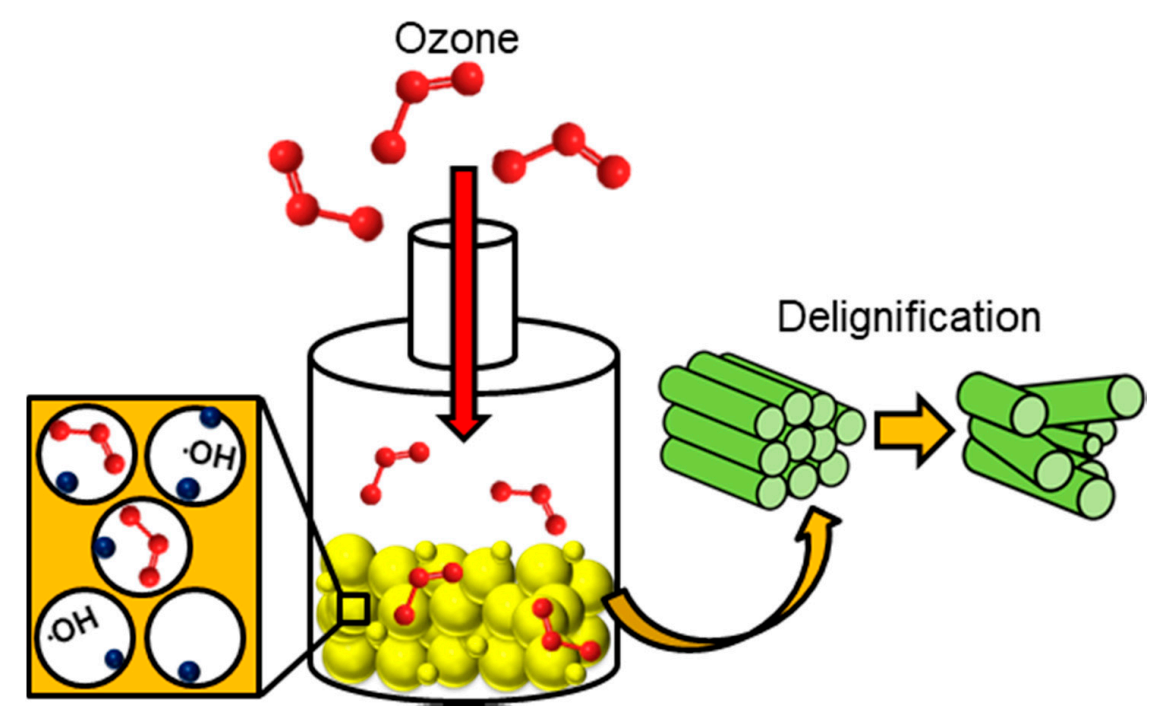

Figure 7. The process of ozonolysis and its effect on both delignification and the formation of hydroxyl radicals within the porous network of the biomass waste particles. Where: biomass waste particles and: water molecule. 


\subsection{Ozonolysis}

As a tool to promote lignin degradation, the use of ozone has gained a lot of attention over the past 20 years as a strong oxidising agent [119]. Due to the electron deficiency of ozone, it will preferentially attack areas of high electron density (e.g., aromatic and phenolic compounds). Therefore, the destruction of lignin is more selective than other areas of degradation in the lignocellulosic waste matrix, this being said, it has been found that hemicellulose can undergo mild alterations, too [13]. This pre-treatment has also been used in conjunction with acid treatments to reduce lignin that is generally acid insoluble [120]. On its own, ozonolysis has been credited as not producing any toxic components for downstream processing [13]. Microscopy techniques have concluded that delignification as a result of ozone has led to a change in the surface structure of the feedstock material, as well as its fibrous nature [64]. Structural alterations due to swelling such as pore expansion from the inherent moisture content (discussed earlier) lead to a greater surface area for ozone interaction. Due to the instability of ozone in water, hydroxyl radicals are readily formed which in their own right act as powerful oxidising agents, accelerating lignin degradation, shown in Figure 7 [121]. However, the cost of generating ozone (both equipment and energy requirements) for the role diminishes its attractiveness as a primary pre-treatment process $[13,121]$. This being said, there are no temperature constraints required for the process to be effective on the substrate. This is a room-temperature pre-treatment procedure that can be carried out in several different reactor configurations. Specifically it has been found that fixed bed reactors are the most effective and can be easily scaled up at industrial scale [119]. This type of reactor has been found to require an operation time of 1-3 $\mathrm{h}$, with lignin decomposition at 34-78\% dependant on the biomass waste feedstock used $[120,121]$.

\subsection{Acidic Pre-Treatment}

Although often labelled as hazardous and materials that cause corrosion, acids are chemical tools that assist in the solubilisation of the solid components of the lignocellulosic matrix of biomass waste $[13,84,87,108,122]$. There are two major variations in the use of acid as a pre-treatment process. The first utilises a high temperature $\left(160-220{ }^{\circ} \mathrm{C}\right)$ with a low acid concentration to encourage the hydrolysis of hemicellulose $[87,123]$. The second variation is the use of low temperature (Ambient- $160{ }^{\circ} \mathrm{C}$ ) with a high acid concentration $[13,84,122,123]$. However, it has been discussed that a high temperature can cause degradation of the hydrolysed products, specifically operating ring opening reactions on sugar derived aromatic molecules [122]. Whereas high acid concentrations can generate xylose-based molecules such as furfural from hemicellulose, although a platform molecule for fine chemical catalytic upgrading, molecules of this type are seen as inhibitors for enzymatic fermentation $[18,123,124]$. Other degradation products observed are acetic acid, hydroxyl-methyl-furfural and various other phenolic compounds [125]. Acetic acid although a product of acid treatment is a common acid used for the pre-treatment process itself [125]. A major downside to the use of concentrated acid is that cellulose can undergo severe degradation, this infers that dilute acids are not only a more selective approach to pre-treatment but are more cost effective for long term use as less corrosion should be encountered [126]. Although a very effective method of chemically pre-treating a feedstock material, the use and recycling of inorganic acids such as $\mathrm{HCl}, \mathrm{H}_{2} \mathrm{SO}_{4}, \mathrm{HNO}_{3}$ and $\mathrm{H}_{3} \mathrm{PO}_{4}$ can be proven very expensive alternatives, as is the use of corrosion resistant equipment and the eventual downstream neutralisation processing (increased further when using concentrated acid) [87]. An alternative to inorganic acids is the use of an organic molecule such as the previously mentioned acetic acid. Other acids of this family that have been considered are propionic, oxalic, formic, maleic, salicylic and fumaric [121,122,126-128]. Organic molecules of this type as seen as weaker acids than their inorganic counterparts, this means that they do not dissociate as readily in water. This comment means that by nature, organic acids are less harsh on their environment thus causing less side reactions and corrosion to the reactor. This being said, the use of less aggressive acids means that the overall concentration must be higher to accomplish similar goals $[126,128]$. 


\subsection{Base Pre-Treatment}

In a similar way as wet oxidation and ozonolysis, alkaline-based pre-treatments of biomass waste have been found to encourage the solubilisation of lignin and hemicellulose [129]. This is accomplished by the cleavage of ester linkages and alkaline saponification of acetyl esters releasing acetate in the absence of high operating temperatures $[126,130]$. In fact, there have been reports of alkaline-based pre-treatments operating in a very broad temperature range between -15 and $210^{\circ} \mathrm{C}[122,126,127,131,132]$. The wide temperature range makes the use of a base as pre-treatment tool very appealing as less energy can be used to accomplish the task at hand as well as being less caustic than highly concentrated acidic alternatives [132]. However, as this form of pre-treatment can occur at room temperature, the residence time is negatively impacted upon as a successful process can take days-weeks to be completed [7,87]. Other than facilitating saponification reactions, alkaline-based treatments have also been found to alter textural properties of the biomass waste material. This is where the internal surface area, pore size and cellulosic crystallinity have been altered $[83,133]$. This is emphasized by a swelling effect that takes place due to the addition of alkaline chemicals [134]. Examples of alkaline chemicals used range from aqueous solutions of $\mathrm{NaOH}, \mathrm{KOH}, \mathrm{Ca}(\mathrm{OH})_{2}, \mathrm{LiOH}$, Urea, $\mathrm{NH}_{4} \mathrm{OH}$ and $\mathrm{Na}_{2} \mathrm{CO}_{3}$ to anhydrous ammonia and hydrazine $[7,24,83,121,122,131,132]$. Previously in this review, the majority of technologies that alter the crystallinity of cellulose cause it to diminish and produce more amorphous regions. However, the addition of an alkaline-based pre-treatment medium to biomass waste has been found to increase the crystallinity by hydrolysing glycosidic linkages in the non-ordered (amorphous) regions of cellulose when operating at a high temperature $\left(121^{\circ} \mathrm{C}\right)[134,135]$.

\subsection{Ionic Liquids}

More recent than other pre-treatment process is the use of ionic liquids. This species of chemicals is often seen as a greener approach to chemical pre-treatment as ionic liquids can act as efficient solvents due to their ability to solubilise crystalline cellulose $[121,136]$. This can be accomplished under very low reaction conditions and can even be used in conjunction with standard laboratory solvents to separate the constituent lignocellulosic components [118]. This is due to their inherently high polarity of the ionic liquid that means lignin specifically can be easily extracted [137]. While the naturally low vapour pressure of the ionic liquid means that they can be recovered relatively easily with a solvent [82]. This means that their usability to upgrade biomass to potential fine chemicals and or future fuels is an attractive concept. The use of ionic liquids in large-scale pre-treatment operations is, however, not currently feasible due to the high initial chemical cost, as well as intensive downstream residue cleaning processes. This said, ionic liquids are recyclable and reusable, increasing their practicality for further investigation. The structure of ionic liquids are pure salts typically based around imidazole as the cationic species, possessing high thermal stabilities $\left(\sim 30{ }^{\circ} \mathrm{C}\right)$ and low melting points (below $\left.100^{\circ} \mathrm{C}\right)[118,136]$. To lower the initial cost of using an ionic liquid, there has been some experimentation into diluting the species in water or other organic solvents, this has also been beneficial in reducing the viscosity of the suspension [138]. However, by conducting the pre-treatment process in this way has been found to diminish the effectivity of the ionic liquid and how it solubilises cellulose [139]. Overcoming the lower activity can lead to higher temperatures required and longer residence times $[82,138]$. General temperatures used for a range of biomass feedstock materials have been in the range of $90-130^{\circ} \mathrm{C}$ [82]. As well as a variable amount of time required between 1 and $24 \mathrm{~h}$ to reach completion $[82,140,141]$.

\subsection{Leaching for Extracting Inorganic Components}

During thermochemical downstream processes such as pyrolysis and gasification, the high temperatures used lead to the full decomposition of the biomass waste. This often leaves behind inorganic components (ash) which have melting points far higher than the carbonaceous matrix of the waste, i.e., $\mathrm{SiO}_{2}, \mathrm{MgO}, \mathrm{CaO}, \mathrm{P}_{2} \mathrm{O}_{5}, \mathrm{~K}_{2} \mathrm{O}$ and $\mathrm{Na}_{2} \mathrm{O}$ as well as other oxides present in much lower concentrations $[142,143]$. The resulting ash formed from biomass waste can build up and deposit on 
the heat exchanger as well as lead to slagging, fouling and corrosion of the reactor and pipes when operating past $800{ }^{\circ} \mathrm{C}$ [144]. For the case of fluidised bed reactors, inorganics can build up causing de-fluidisation and bed agglomeration $[142,145]$. Other elements such as $\mathrm{Cl}$ and $\mathrm{S}$ can also present negative effects to the overall process as well as cause deactivation/poisoning of the heterogeneous catalyst if used during fast pyrolysis [146]. High concentrations of alkali metals can promote fragmentation-based side reaction pathways during catalytic upgrading such as cellulose ring-scission [147-149]. Gas and liquid phase by-products generated can be toxic by nature and, therefore, a cause for environmental concern [142]. However, low alkali content in the feedstock can facilitate depolymerisation of the cellulose component $[148,149]$.

Overcoming issues caused by inorganic residues is a necessary requirement for thermochemical downstream valorisation [150]. A method to accomplish this is leaching, also referred to as a 'washing pre-treatment' [151]. This is where the waste material is submerged and agitated in a liquid medium such as de-ionised (demineralised) water or acidic species, examples of acids used are acetic, citric, hydrochloric and sulphuric acid [142,148,150-156]. Recently, there has also been work carried using an aqueous phase bio-oil with a high water content (73.2 $\mathrm{wt} \%$ ) and inherently low $\mathrm{pH}(2.9)$ as an inorganic leaching medium [151]. During the pre-treatment process the solvent used will enter the porous network in a similar manner to other physicochemical and chemical treatments, swelling the structure (increasing both pore volume and available surface area) and reducing the cellulose crystallinity. This is shown in Figure 8, where blue arrows are the solvent entering and red arrows are the leachate leaving the waste particles. As the solvent diffuses through the material, inorganic material will be transferred into the leachate [157]. Identical with other processes is that the temperature, residence time, solvent used and agitation rate governs the effectivity of the pre-treatment [158]. Temperature is particularly vital albeit not as high as many of the other pre-treatment processes. Often occurring at room or ambient temperatures, leaching has taken place between 15 and $90{ }^{\circ} \mathrm{C}[144,151,153,156,159,160]$. It is understood that higher temperatures used for leaching can enable the removal of $\mathrm{SiO}_{2}$, depending on the bonding strength of the silica to the organic substrate [159]. Higher temperature washing pre-treatments in water have also been found to benefit the removal of $\mathrm{S}, \mathrm{K}$ and $\mathrm{Cl}$ in both the substrate and produced char from pyrolysis by up to $90 \%$ [159-161]. Care must be taken when operating at high temperatures as the solubilisation of hemicellulose can take place, as discussed previously for hot water treatments. Combining size reduction techniques with leaching pre-treatments has been found to enhance the removal of rogue elements such as $\mathrm{Mg}, \mathrm{Na}, \mathrm{K}, \mathrm{P}, \mathrm{S}$ and $\mathrm{Cl}[162]$. This is due to a greater surface area to volume ratio for the solvent to penetrate the substrate and facilitate removal of inorganic constituents.

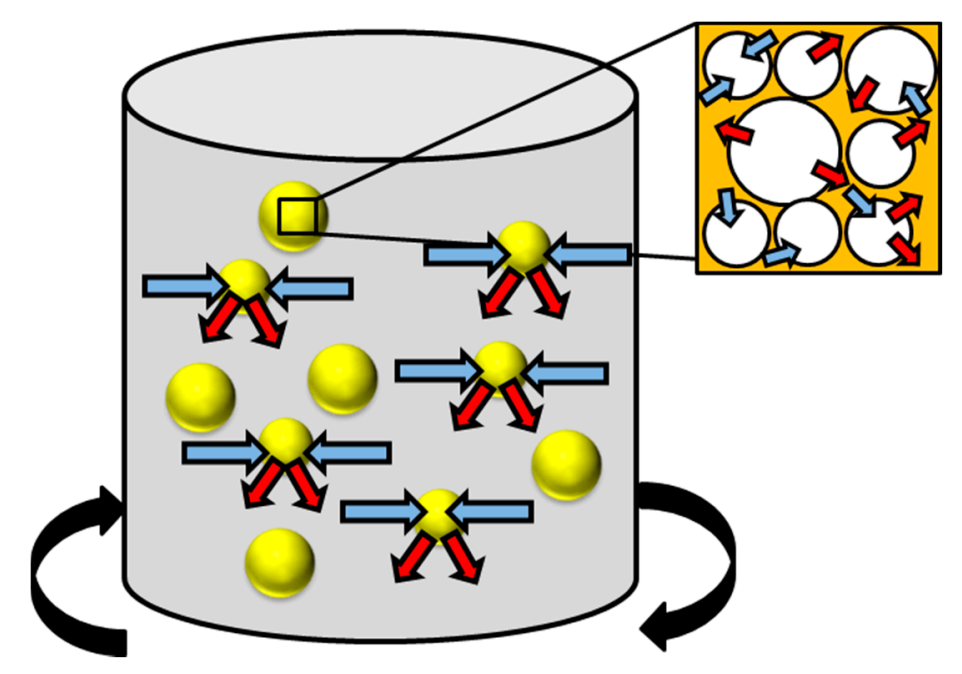

Figure 8. The general process of leaching where the solvent enters the waste particle (blue arrow) and the leachate (red arrow) leaves the biomass waste particle. Where: biomass waste particles. 


\section{Other Forms of Lignocellulosic Waste Pre-Treatments}

After considering the more mainstream methods of physical, physicochemical and chemical pre-treatment, there are several novel techniques which have been explored in recent years that have yielded promising results. By exploiting modern technologies such as linear accelerators, high intensity radioactive sources and electricity, the waste material can be rapidly modified without the need to use additional or tandem methods of pre-treatment, unlike others mentioned previously.

\subsection{Pulsed Electric Field (PEF)}

Pulsed Electric Field (PEF) pre-treatment procedures operate in a similar way to the directed ultrasonic probe albeit in a fraction of a second (each pulse lasting for 100-800 $\mu \mathrm{s}$ ), while operating at a field strength between 0.5 and $50 \mathrm{kV} \mathrm{cm}^{-1}$ [163-166]. This novel pre-treatment process is where a solid sample is placed between two electrodes, typically spaced $\sim 5 \mathrm{~cm}$ apart [166]. Here, a high voltage is discharged between the anode and cathode under ambient conditions. The biomass, situated between the probes undergoes rapid breakdown as the porous network ruptures $[7,163]$. The electrical discharge has been found to perforate the structure of the substrate. This is where pores are dramatically opened or new cavities are formed (similar to explosion treatments highlighted in Figure 4) [7]. Extreme perforation of the porous network can allow for follow up pre-treatments such as acid hydrolysis to be more effective than when carried out before PEF. However, any of the treatments listed previously that utilise the porous structure of the feedstock material could benefit from this method of physical treatment. Kumar et al. have found that utilising 2000 pulses at a field strength of $10 \mathrm{kV} \mathrm{cm}^{-1}$ can improve the hydrolysis of cellulose for upgrading [51,163,164]. In addition to assisting the diffusion of soluble molecules throughout the substrate, this pre-treatment process can also facilitate in improved dehydration as the energy put into the material generates a large hot spot, reducing moisture content [7].

\subsection{Electron Beam}

Often used for the irradiation of contaminated materials for sterilisation, radiation processing is an interesting method of pre-treatment [167]. By using a linear accelerator (LINAC), a beam of high energy electrons $(<10 \mathrm{MeV})$ can be generated [167-169]. The electrons are passed solely along a linear beamline in a series of segments which have variable magnetic polarities. Although not as penetrating as other forms of radiation such as gamma, the electron beam is able to interact with moisture in the substrate, forming radicals in a similar approach to other processes. Similar to microwave irradiation, the use of an electron beam can be considered a physicochemical process, albeit without the need for pressure and temperature constraints. This is where the beam physically alters the material by irradiating it with 10-1000 kGy, causing a chemical transformation [126,167,170]. Although this pre-treatment process is often seen purely as a physical approach that can improve the accessible surface area of the substrate for biological processing [171]. However, for thermochemical processing, the use of an electron beam can cause polymer degradation [172]. This means that bond breaking between cellulose and hemicellulose will occur due to an increase in water-based reactions [167]. This also means that cellulose crystallinity can be decreased, as well as alterations in the hemicellulose and lignin matrix due to OH-radicals causing solubilization [168]. This method has also been found when in conjunction with base $(\mathrm{NaOH})$ to destabilize the linkages between the components [173]. This method of pre-treatment could be an effective tool for large-scale use. However, the cost of installing and operating a LINAC is not feasible, additionally the radiation exposure must be closely monitored as over irradiating the substrate can lead to full decomposition [174].

\subsection{Gamma Irradiation ( $\gamma$-Irradiation)}

Another electromagnetic-based method of pre-treatment that utilises highly penetrating radiation is the use of gamma rays [170]. A radioactive source such as Co-60 or Cs-137 have been considered 
as a source of high energy photons as they undergo decay $[164,167,170]$. Ionizing radiation of this type has been found to destabilise the lignocellulosic matrix, this means that instead of the individual components breaking down or solubilising as seen by other pre-treatments, the encapsulation of cellulose by hemicellulose and lignin is weakened so that the individual components are more accessible, or less energy is required to breakdown the material thermochemically. Gamma irradiation has also been found to lower the overall degree of polymerisation specifically between cellulose and lignin [170]. By not digesting or solubilising an individual part, this method of pre-treatment on its own could be useful for thermochemical processing such as pyrolysis or gasification. In conjunction with other pre-treatment processes, ionization of this type can enhance solubilization, disintegration and hydrolysis reactions, this is also useful for the biochemical processing [175]. However, similarly with electron beam treatments, if the intensity and residence time is high enough, the overall polymeric structure will degrade, and the organic matter will be digested. Khan found that the combination of $\gamma$-rays with an oxygen rich environment will generate energetic peroxide-based radicals within the lignocellulosic waste matrix [176]. These entities are very destructive and will cause bond breakages throughout the substrate [170]. The thermal stability of a herbaceous waste material such as rapeseed straw when exposed to $1200 \mathrm{kGy}$ has been found to decrease, along with the size of the particles, while increasing the overall surface area [164]. The time taken for this kind of pre-treatment is dependent on the rate or irradiation, where a mild dose at a high rate can be completed in a few minutes and a larger dose can require a few hours at a similar rate [177].

\section{Conclusions}

A variety of physical, physicochemical and chemical pre-treatments of lignocellulosic waste aiming at upgrading them to suitable solid fuels have been discussed and reviewed depending on their ability and feasibility when considering a process route for an optimised downstream thermochemical and at a lesser extent for biochemical operation. Starting with the reduction of inherent moisture and the particle size of lignocellulosic biomass waste, the feedstock can undergo a method of physicochemical or chemical treatment to fully optimise them as a solid fuel for downstream valorisation for energy production. For most of the review, each technique has been considered independent to the next. However, numerous lignocellulosic waste pre-treatment technologies can be combined to suit the desired downstream operation (thermochemical or biochemical). Specifically, for thermochemical processing such as pyrolysis, gasification and combustion, the reduction/solubilisation of an individual component is not desired. These pre-treatments are better suited for biological upgrading for ethanol production and enzymatic processes. Mechanical/physical treatments for particle size alterations and general methods to reduce the level of polymerisation such as dilute acids/bases, ozonolysis, microwave irradiation or steam explosion could be proven the most effective, whereas stronger acid treatments or $\mathrm{CO}_{2}$ explosions which generate acidic species within the porous structure can produce a wide array of platform/transient molecules in the liquid bio-oil for potential downstream reformation post pyrolysis. It is clear that for the benefit of both the equipment (lack of corrosion and blockages) as well as the full utilisation of the bio-derived feedstock, a method of leaching or washing must take place. The absence of inorganic constituents from the biomass waste matrix has been found to reduce ash effect and limit alkali metals in the produced char. Simple, low cost methods of leaching have been mentioned, where a combination with other techniques such as milling and the addition of dilute acid could prove the most effective of all for the pre-treatments of waste materials for especially thermochemical valorisation.

Author Contributions: All authors contributed to all aspects of the review, and specifically: conceptualization, V.S.; methodology, V.S. and M.J.T.; formal analysis, investigation, resources, and data curation V.S., M.J.T. and H.A.A.; writing—original draft preparation V.S., M.J.T. and H.A.A.; writing—review and editing, V.S. and M.J.T.; visualization, M.J.T. and H.A.A.; supervision, project administration and funding acquisition V.S.

Funding: This research was funded by Engineering and Physical Sciences Research Council (EPSRC) of UK, under the funding scheme of the New Investigator Grant (former First Grant), grant number EP/P034667/1. 
Acknowledgments: Special thanks are devoted to P.Manara, CPERI CERTH Institute, Greece for her constructive feedback in the field of microwave pre-treatment of lignocellulosic waste and delignification treatments.

Conflicts of Interest: The authors declare no conflict of interest.

\section{References}

1. Sarkar, M.; Kumar, A.; Tumuluru, J.S.; Patil, K.N.; Bellmer, D.D. Gasification performance of switchgrass pretreated with torrefaction and densification. Appl. Energy 2014, 127, 194-201. [CrossRef]

2. Basu, P. Biomass Gasification, Pyrolysis and Torrefaction: Practical Design and Theory, 2nd ed.; Elsevier Science: London, UK, 2013.

3. Kumari, D.; Singh, R. Pretreatment of lignocellulosic wastes for biofuel production: A critical review. Renew. Sustain. Energy Rev. 2018, 90, 877-891. [CrossRef]

4. Popp, J.; Lakner, Z.; Harangi-Rakos, M.; Fari, M. The effect of bioenergy expansion: Food, energy, and environment. Renew. Sustain. Energy Rev. 2014, 32, 559-578. [CrossRef]

5. Slade, R.; Saunders, R.; Gross, R.; Bauen, A. Energy from Biomass: The size of the Global Resource; Imperial College Centre for Energy Policy and Technology and UK Energy Research Centre: London, UK, 2011.

6. Sharif, A.; Raza, S.A.; Ozturk, I.; Afshan, S. The dynamic relationship of renewable and nonrenewable energy consumption with carbon emission: A global study with the application of heterogeneous panel estimations. Renew. Energy 2019, 133, 685-691. [CrossRef]

7. Kumar, P.; Barrett, D.M.; Delwiche, M.J.; Stroeve, P. Methods for Pretreatment of Lignocellulosic Biomass for Efficient Hydrolysis and Biofuel Production. Ind. Eng. Chem. Res. 2009, 48, 3713-3729. [CrossRef]

8. Chen, H.Y.; Liu, J.B.; Chang, X.; Chen, D.M.; Xue, Y.; Liu, P.; Lin, H.L.; Han, S. A review on the pretreatment of lignocellulose for high-value chemicals. Fuel Process. Technol. 2017, 160, 196-206. [CrossRef]

9. Skoulou, V.; Zabaniotou, A.; Stavropoulos, G.; Sakelaropoulos, G. Syngas production from olive tree cuttings and olive kernels in a downdraft fixed-bed gasifier. Int. J. Hydrogen Energy 2008, 33, 1185-1194. [CrossRef]

10. Zabaniotou, A.A.; Skoulou, V.K.; Mertzis, D.P.; Koufodimos, G.S.; Samaras, Z.C. Mobile Gasification Units for Sustainable Electricity Production in Rural Areas: The SMARt-CHP Project. Ind. Eng. Chem. Res. 2011, 50, 602-608. [CrossRef]

11. Zabaniotou, A.; Skoulou, V.; Koufodimos, G.; Samaras, Z. Investigation study for technological application of alternative methods for the energy exploitation of biomass/agricultural residues in Northern Greece. Therm. Sci. 2007, 11, 115-123. [CrossRef]

12. Volpe, R.; Zabaniotou, A.A.; Skoulou, V. Synergistic Effects between Lignin and Cellulose during Pyrolysis of Agricultural Waste. Energy Fuels 2018, 32, 8420-8430. [CrossRef]

13. Sun, Y.; Cheng, J. Hydrolysis of lignocellulosic materials for ethanol production: A review. Bioresour. Technol. 2002, 83, 1-11. [CrossRef]

14. Widjaya, E.R.; Chen, G.N.; Bowtell, L.; Hills, C. Gasification of non-woody biomass: A literature review. Renew. Sustain. Energy Rev. 2018, 89, 184-193. [CrossRef]

15. Satari, B.; Karimi, K.; Kumar, R. Cellulose solvent-based pretreatment for enhanced second-generation biofuel production: A review. Sustain. Energy Fuels 2019, 3, 11-62. [CrossRef]

16. Chan, Y.H.; Cheah, K.W.; How, B.S.; Loy, A.C.M.; Shahbaz, M.; Singh, H.K.G.; Yusuf, N.R.; Shuhaili, A.F.A.; Yusup, S.; Ghani, W.; et al. An overview of biomass thermochemical conversion technologies in Malaysia. Sci. Total Environ. 2019, 680, 105-123. [CrossRef] [PubMed]

17. Hellier, P.; Talibi, M.; Eveleigh, A.; Ladommatos, N. An overview of the effects of fuel molecular structure on the combustion and emissions characteristics of compression ignition engines. Proc. Inst. Mech. Eng. Part D J. Automob. Eng. 2018, 232, 90-105. [CrossRef]

18. Taylor, M.J.; Durndell, L.J.; Isaacs, M.A.; Parlett, C.M.A.; Wilson, K.; Lee, A.F.; Kyriakou, G. Highly selective hydrogenation of furfural over supported Pt nanoparticles under mild conditions. Appl. Catal. B Environ. 2016, 180, 580-585. [CrossRef]

19. Serrano-Ruiz, J.C.; Luque, R.; Sepulveda-Escribano, A. Transformations of biomass-derived platform molecules: From high added-value chemicals to fuels via aqueous-phase processing. Chem. Soc. Rev. 2011, 40, 5266-5281. [CrossRef] [PubMed]

20. Mohan, D.; Pittman, C.U.; Steele, P.H. Pyrolysis of wood/biomass for bio-oil: A critical review. Energy Fuels 2006, 20, 848-889. [CrossRef] 
21. Bridgwater, A.V. Review of fast pyrolysis of biomass and product upgrading. Biomass Bioenergy 2012, 38, 68-94. [CrossRef]

22. Yan, K.; Wu, G.; Lafleur, T.; Jarvis, C. Production, properties and catalytic hydrogenation of furfural to fuel additives and value-added chemicals. Renew. Sustain. Energy Rev. 2014, 38, 663-676. [CrossRef]

23. Yan, K.; Jarvis, C.; Gu, J.; Yan, Y. Production and catalytic transformation of levulinic acid: A platform for speciality chemicals and fuels. Renew. Sustain. Energy Rev. 2015, 51, 986-997. [CrossRef]

24. Das, P.; Stoffel, R.B.; Area, M.C.; Ragauskas, A.J. Effects of one-step alkaline and two-step alkaline/dilute acid and alkaline/steam explosion pretreatments on the structure of isolated pine lignin. Biomass Bioenergy 2019, 120, 350-358. [CrossRef]

25. Sakaguchi, M.; Watkinson, A.P.; Ellis, N. Steam Gasification of Bio-Oil and Bio-Oil/Char Slurry in a Fluidized Bed Reactor. Energy Fuels 2010, 24, 5181-5189. [CrossRef]

26. Skoulou, V.; Zabaniotou, A. Fe catalysis for lignocellulosic biomass conversion to fuels and materials via thermochemical processes. Catal. Today 2012, 196, 56-66. [CrossRef]

27. Qu, T.J.; Zhang, X.M.; Gu, X.W.; Han, L.J.; Ji, G.Y.; Chen, X.L.; Xiao, W.H. Ball Milling for Biomass Fractionation and Pretreatment with Aqueous Hydroxide Solutions. ACS Sustain. Chem. Eng. 2017, 5, 7733-7742. [CrossRef]

28. Demirhan, H.; Fauzi, A.; Skoulou, V.K.; Haywood, S.H.; Zein, S.H. Wheat Straw Bio-refining. Part I: Optimization of the Microwave Radiation Process with Sulphuric Acid Pre-treatment. Curr. Microw. Chem. 2017, 4, 205-218. [CrossRef]

29. Song, Y.; Mobley, J.K.; Motagamwala, A.H.; Isaacs, M.A.; Dumesic, J.A.; Ralph, J.; Lee, A.F.; Wilson, K.; Crocker, M. Gold-catalyzed conversion of lignin to low molecular weight aromatics. Chem. Sci. 2018, 9, 8127-8133. [CrossRef] [PubMed]

30. Vanholme, R.; Demedts, B.; Morreel, K.; Ralph, J.; Boerjan, W. Lignin biosynthesis and structure. Plant Physiol. 2010, 153, 895-905. [CrossRef]

31. Guerra, A.; Mendonca, R.; Ferraz, A.; Lu, F.; Ralph, J. Structural characterization of lignin during Pinus taeda wood treatment with Ceriporiopsis subvermispora. Appl. Environ. Microbiol. 2004, 70, 4073-4078. [CrossRef]

32. Zhou, X.; Broadbelt, L.J.; Vinu, R. Mechanistic Understanding of Thermochemical Conversion of Polymers and Lignocellulosic Biomass. Adv. Chem. Eng. 2016, 49, 95-198. [CrossRef]

33. Ranzi, E.; Cuoci, A.; Faravelli, T.; Frassoldati, A.; Migliavacca, G.; Pierucci, S.; Sommariva, S. Chemical Kinetics of Biomass Pyrolysis. Energy Fuels 2008, 22, 4292-4300. [CrossRef]

34. Zhang, X.L.; Yang, W.H.; Blasiak, W. Modeling Study of Woody Biomass: Interactions of Cellulose, Hemicellulose, and Lignin. Energy Fuels 2011, 25, 4786-4795. [CrossRef]

35. Bajpai, P. Structure of Lignocellulosic Biomass. In Pretreatment of Lignocellulosic Biomass for Biofuel Production, 1st ed.; Springer: Singapore, 2016.

36. Zhuang, X.; Wang, W.; Yu, Q.; Qi, W.; Wang, Q.; Tan, X.; Zhou, G.; Yuan, Z. Liquid hot water pretreatment of lignocellulosic biomass for bioethanol production accompanying with high valuable products. Bioresour. Technol. 2016, 199, 68-75. [CrossRef] [PubMed]

37. Yoshida, M.; Liu, Y.; Uchida, S.; Kawarada, K.; Ukagami, Y.; Ichinose, H.; Kaneko, S.; Fukuda, K. Effects of cellulose crystallinity, hemicellulose, and lignin on the enzymatic hydrolysis of Miscanthus sinensis to monosaccharides. Biosci. Biotechnol. Biochem. 2008, 72, 805-810. [CrossRef] [PubMed]

38. Baruah, J.; Nath, B.K.; Sharma, R.; Kumar, S.; Deka, R.C.; Baruah, D.C.; Kalita, E. Recent Trends in the Pretreatment of Lignocellulosic Biomass for Value-Added Products. Front. Energy Res. 2018, 6. [CrossRef]

39. Fang, Z. Pretreatment Techniques for Biofuels and Biorefineries; Springer: Berlin/Heidelberg, Germany, 2013.

40. Karimi, K.; Taherzadeh, M.J. A critical review of analytical methods in pretreatment of lignocelluloses: Composition, imaging, and crystallinity. Bioresour. Technol. 2016, 200, 1008-1018. [CrossRef] [PubMed]

41. Sathitsuksanoh, N.; Zhu, Z.; Wi, S.; Zhang, Y.H. Cellulose solvent-based biomass pretreatment breaks highly ordered hydrogen bonds in cellulose fibers of switchgrass. Biotechnol. Bioeng. 2011, 108, 521-529. [CrossRef]

42. Esteghlalian, A.R.; Bilodeau, M.; Mansfield, S.D.; Saddler, J.N. Do enzymatic hydrolyzability and Simons' stain reflect the changes in the accessibility of lignocellulosic substrates to cellulase enzymes? Biotechnol. Prog. 2001, 17, 1049-1054. [CrossRef] [PubMed]

43. Yoon, H.H.; Wu, Z.W.; Lee, Y.Y. Ammonia-Recycled Percolation Process for Pretreatment of Biomass Feedstock. Appl. Biochem. Biotechnol. 1995, 51-52, 5-19. [CrossRef] 
44. Nunes, L.J.R.; Matias, J.C.O.; Catalao, J.P.S. A review on torrefied biomass pellets as a sustainable alternative to coal in power generation. Renew. Sustain. Energy Rev. 2014, 40, 153-160. [CrossRef]

45. Mobini, M.; Meyer, J.C.; Trippe, F.; Sowlati, T.; Frohling, M.; Schultmann, F. Assessing the integration of torrefaction into wood pellet production. J. Clean. Prod. 2014, 78, 216-225. [CrossRef]

46. Fantini, M. Biomass Availability, Potential and Characteristics. In Biorefineries, 1st ed.; Rabaçal, M., Ferreira, A.F., Silva, C.A.M., Costa, M., Eds.; Springer: Cham, Switzerland, 2017; Volume 57, pp. 21-54.

47. Shankar Tumuluru, J.; T Wright, C.; Boardman, R.D.; Yancey, N.A.; Sokhansanj, S. A review on biomass classification and composition, co-firing issues and pretreatment methods. In Proceedings of the 2011 ASABE Annual International Meeting, Louisville, KY, USA, 7-10 August 2011.

48. Barakat, A.; Mayer-Laigle, C.; Solhy, A.; Arancon, R.A.D.; de Vries, H.; Luque, R. Mechanical pretreatments of lignocellulosic biomass: Towards facile and environmentally sound technologies for biofuels production. RSC Adv. 2014, 4, 48109-48127. [CrossRef]

49. Kamarludin, S.N.C.; Jainal, M.S.; Azizan, A.; Safaai, N.S.M.; Daud, A.R.M. Mechanical Pretreatment of Lignocellulosic Biomass For Biofuel Production. Appl. Mech. Mater. 2014, 625, 838-841. [CrossRef]

50. Zakaria, M.R.; Fujimoto, S.; Hirata, S.; Hassan, M.A. Ball milling pretreatment of oil palm biomass for enhancing enzymatic hydrolysis. Appl. Biochem. Biotechnol. 2014, 173, 1778-1789. [CrossRef] [PubMed]

51. Kumar, A.K.; Sharma, S. Recent updates on different methods of pretreatment of lignocellulosic feedstocks: A review. Bioresour. Bioprocess. 2017, 4, 7. [CrossRef] [PubMed]

52. Yuan, X.L.; Liu, S.J.; Feng, G.R.; Liu, Y.Y.; Li, Y.D.; Lu, H.F.; Liang, B. Effects of ball milling on structural changes and hydrolysis of lignocellulosic biomass in liquid hot-water compressed carbon dioxide. Korean J. Chem. Eng. 2016, 33, 2134-2141. [CrossRef]

53. Chang, V.S.; Nagwani, M.; Kim, C.-H.; Holtzapple, M.T. Oxidative lime pretreatment of high-lignin biomass. Appl. Biochem. Biotechnol. 2000, 94,1-28. [CrossRef]

54. Nuruddin, M.; Hosur, M.; Uddin, M.J.; Baah, D.; Jeelani, S. A novel approach for extracting cellulose nanofibers from lignocellulosic biomass by ball milling combined with chemical treatment. J. Appl. Polym. Sci. 2015, 133, 42990-43000. [CrossRef]

55. Kim, S.M.; Dien, B.S.; Singh, V. Promise of combined hydrothermal/chemical and mechanical refining for pretreatment of woody and herbaceous biomass. Biotechnol. Biofuels 2016, 9, 97. [CrossRef]

56. Qu, Y.; Luo, H.; Li, H.; Xu, J. Comparison on structural modification of industrial lignin by wet ball milling and ionic liquid pretreatment. Biotechnol. Rep. 2015, 6, 1-7. [CrossRef]

57. Zhou, J.; Chen, D.; Zhu, Y.; Liao, H.; Yuan, L.; Chen, Z.; Liu, X. Simultaneous wet ball milling and mild acid hydrolysis of rice hull. J. Chem. Technol. Biotechnol. 2009, 85, 85-90. [CrossRef]

58. Yamashita, Y.; Sasaki, C.; Nakamura, Y. Development of efficient system for ethanol production from paper sludge pretreated by ball milling and phosphoric acid. Carbohydr. Polym. 2010, 79, 250-254. [CrossRef]

59. Schell, D.J.; Harwood, C. Milling of Lignocellulosic Biomass-Results of Pilot-Scale Testing. Appl. Biochem. Biotechnol. 1994, 45-46, 159-168. [CrossRef]

60. Teixeira, R.S.; da Silva, A.S.; Jang, J.H.; Kim, H.W.; Ishikawa, K.; Endo, T.; Lee, S.H.; Bon, E.P. Combining biomass wet disk milling and endoglucanase/beta-glucosidase hydrolysis for the production of cellulose nanocrystals. Carbohydr. Polym. 2015, 128, 75-81. [CrossRef] [PubMed]

61. Fu, Y.; Gu, B.J.; Wang, J.; Gao, J.; Ganjyal, G.M.; Wolcott, M.P. Novel micronized woody biomass process for production of cost-effective clean fermentable sugars. Bioresour. Technol. 2018, 260, 311-320. [CrossRef] [PubMed]

62. Corbett, D.B.; Venditti, R.; Jameel, H.; Park, S. Effect of Mechanical Refining Energy on the Enzymatic Digestibility of Lignocellulosic Biomass. Ind. Eng. Chem. Res. 2018, 57, 14648-14655. [CrossRef]

63. Chen, X.; Kuhn, E.; Wang, W.; Park, S.; Flanegan, K.; Trass, O.; Tenlep, L.; Tao, L.; Tucker, M. Comparison of different mechanical refining technologies on the enzymatic digestibility of low severity acid pretreated corn stover. Bioresour. Technol. 2013, 147, 401-408. [CrossRef] [PubMed]

64. de Barros Rda, R.; Paredes Rde, S.; Endo, T.; Bon, E.P.; Lee, S.H. Association of wet disk milling and ozonolysis as pretreatment for enzymatic saccharification of sugarcane bagasse and straw. Bioresour. Technol. 2013, 136, 288-294. [CrossRef]

65. Rizal, N.; Ibrahim, M.F.; Zakaria, M.R.; Abd-Aziz, S.; Yee, P.L.; Hassan, M.A. Pre-treatment of Oil Palm Biomass for Fermentable Sugars Production. Molecules 2018, 23, 1381. [CrossRef] 
66. Karinkanta, P.; Ammala, A.; Illikainen, M.; Niinimaki, J. Fine grinding of wood-Overview from wood breakage to applications. Biomass Bioenergy 2018, 113, 31-44. [CrossRef]

67. Tumuluru, J.S. Effect of Moisture Content and Hammer Mill Screen Size on the Briquetting Characteristics of Woody and Herbaceous Biomass. KONA Powder Part. J. 2019, 36, 241-251. [CrossRef]

68. Mani, S.; Tabil, L.G.; Sokhansanj, S. Effects of compressive force, particle size and moisture content on mechanical properties of biomass pellets from grasses. Biomass Bioenergy 2006, 30, 648-654. [CrossRef]

69. Ämmälä, A.; Pääkkönen, T.M.; Illikainen, M. Role of screen plate design in the performance of a rotor impact mill in fine grinding of biomass. Ind. Crops Prod. 2018, 122, 384-391. [CrossRef]

70. Mayer-Laigle, C.; Rajaonarivony, R.K.; Blanc, N.; Rouau, X. Comminution of Dry Lignocellulosic Biomass: Part II. Technologies, Improvement of Milling Performances, and Security Issues. Bioengineering 2018, 5, 50. [CrossRef] [PubMed]

71. Silva, G.G.; Couturier, M.; Berrin, J.G.; Buleon, A.; Rouau, X. Effects of grinding processes on enzymatic degradation of wheat straw. Bioresour. Technol. 2012, 103, 192-200. [CrossRef] [PubMed]

72. Chamayou, A.; Dodds, J.A. Chapter 8 Air Jet Milling. In Handbook of Powder Technology; Salman, A.D., Ghadiri, M., Hounslow, M.J., Eds.; Elsevier Science B.V.: Amsterdam, The Netherlands, 2007.

73. Negro, M.J.; Duque, A.; Manzanares, P.; Saez, F.; Oliva, J.M.; Ballesteros, I.; Ballesteros, M. Alkaline twin-screw extrusion fractionation of olive-tree pruning biomass. Ind. Crops Prod. 2015, 74, 336-341. [CrossRef]

74. Patil, H.; Tiwari, R.V.; Repka, M.A. Hot-Melt Extrusion: From Theory to Application in Pharmaceutical Formulation. AAPS PharmSciTech 2016, 17, 20-42. [CrossRef] [PubMed]

75. Duque, A.; Manzanares, P.; González, A.; Ballesteros, M. Study of the Application of Alkaline Extrusion to the Pretreatment of Eucalyptus Biomass as First Step in a Bioethanol Production Process. Energies 2018, 11, 2961. [CrossRef]

76. Zheng, J.; Rehmann, L. Extrusion pretreatment of lignocellulosic biomass: A review. Int. J. Mol. Sci. 2014, 15, 18967-18984. [CrossRef]

77. Michopoulos, A.; Skoulou, V.; Voulgari, V.; Tsikaloudaki, A.; Kyriakis, N.A. The exploitation of biomass for building space heating in Greece: Energy, environmental and economic considerations. Energy Convers. Manag. 2014, 78, 276-285. [CrossRef]

78. Chen, X.H.; Zhang, Y.L.; Gu, Y.; Liu, Z.G.; Shen, Z.; Chu, H.Q.; Zhou, X.F. Enhancing methane production from rice straw by extrusion pretreatment. Appl. Energy 2014, 122, 34-41. [CrossRef]

79. Gatt, E.; Rigal, L.; Vandenbossche, V. Biomass pretreatment with reactive extrusion using enzymes: A review. Ind. Crops Prod. 2018, 122, 329-339. [CrossRef]

80. Vandenbossche, V.; Brault, J.; Vilarem, G.; Hernandez-Melendez, O.; Vivaldo-Lima, E.; Hernandez-Luna, M.; Barzana, E.; Duque, A.; Manzanares, P.; Ballesteros, M.; et al. A new lignocellulosic biomass deconstruction process combining thermo-mechano chemical action and bio-catalytic enzymatic hydrolysis in a twin-screw extruder. Ind. Crops Prod. 2014, 55, 258-266. [CrossRef]

81. Zhao, W.; Yang, R.J.; Zhang, Y.Q.; Wu, L. Sustainable and practical utilization of feather keratin by an innovative physicochemical pretreatment: High density steam flash-explosion. Green Chem. 2012, 14, 3352-3360. [CrossRef]

82. Brodeur, G.; Yau, E.; Badal, K.; Collier, J.; Ramachandran, K.B.; Ramakrishnan, S. Chemical and physicochemical pretreatment of lignocellulosic biomass: A review. Enzym. Res. 2011, 2011, 787532. [CrossRef]

83. Agbor, V.B.; Cicek, N.; Sparling, R.; Berlin, A.; Levin, D.B. Biomass pretreatment: Fundamentals toward application. Biotechnol. Adv. 2011, 29, 675-685. [CrossRef]

84. Mood, S.H.; Golfeshan, A.H.; Tabatabaei, M.; Jouzani, G.S.; Najafi, G.; Gholami, M.; Ardjmand, M. Lignocellulosic biomass to bioethanol, a comprehensive review with a focus on pretreatment. Renew. Sustain. Energy Rev. 2013, 27, 77-93. [CrossRef]

85. Yu, Z.; Zhang, B.; Yu, F.; Xu, G.; Song, A. A real explosion: The requirement of steam explosion pretreatment. Bioresour. Technol. 2012, 121, 335-341. [CrossRef]

86. Datar, R.; Huang, J.; Maness, P.-C.; Mohagheghi, A.; Czernik, S.; Chornet, E. Hydrogen production from the fermentation of corn stover biomass pretreated with a steam-explosion process. Int. J. Hydrogen Energy 2006, 32, 932-939. [CrossRef]

87. Mosier, N.; Wyman, C.; Dale, B.; Elander, R.; Lee, Y.Y.; Holtzapple, M.; Ladisch, M. Features of promising technologies for pretreatment of lignocellulosic biomass. Bioresour. Technol. 2005, 96, 673-686. [CrossRef] 
88. Zheng, Y.; Lin, H.; Tsao, G.T. Pretreatment for cellulose hydrolysis by carbon dioxide explosion. Biotechnol. Prog. 1998, 14, 890-896. [CrossRef] [PubMed]

89. Cha, Y.L.; Yang, J.; Ahn, J.W.; Moon, Y.H.; Yoon, Y.M.; Yu, G.D.; An, G.H.; Choi, I.H. The optimized CO2-added ammonia explosion pretreatment for bioethanol production from rice straw. Bioprocess Biosyst. Eng. 2014, 37, 1907-1915. [CrossRef] [PubMed]

90. Kim, K.H.; Hong, J. Supercritical CO2 pretreatment of lignocellulose enhances enzymatic cellulose hydrolysis. Bioresour. Technol. 2001, 77, 139-144. [CrossRef]

91. Mathew, A.K.; Parameshwaran, B.; Sukumaran, R.K.; Pandey, A. An evaluation of dilute acid and ammonia fiber explosion pretreatment for cellulosic ethanol production. Bioresour. Technol. 2016, 199, 13-20. [CrossRef] [PubMed]

92. Chundawat, S.P.S.; Donohoe, B.S.; da Costa Sousa, L.; Elder, T.; Agarwal, U.P.; Lu, F.; Ralph, J.; Himmel, M.E.; Balan, V.; Dale, B.E. Multi-scale visualization and characterization of lignocellulosic plant cell wall deconstruction during thermochemical pretreatment. Energy Environ. Sci. 2011, 4, 973-984. [CrossRef]

93. Hatfield, R.D.; Rancour, D.M.; Marita, J.M. Grass Cell Walls: A Story of Cross-Linking. Front. Plant Sci. 2016, 7, 2056. [CrossRef]

94. Li, M.; Cao, S.; Meng, X.; Studer, M.; Wyman, C.E.; Ragauskas, A.J.; Pu, Y. The effect of liquid hot water pretreatment on the chemical-structural alteration and the reduced recalcitrance in poplar. Biotechnol. Biofuels 2017, 10, 237. [CrossRef]

95. Diaz, A.B.; Moretti, M.M.; Bezerra-Bussoli, C.; Carreira Nunes Cda, C.; Blandino, A.; da Silva, R.; Gomes, E. Evaluation of microwave-assisted pretreatment of lignocellulosic biomass immersed in alkaline glycerol for fermentable sugars production. Bioresour. Technol. 2015, 185, 316-323. [CrossRef]

96. Zhu, Z.; Macquarrie, D.J.; Simister, R.; Gomez, L.D.; McQueen-Mason, S.J. Microwave assisted chemical pretreatment of Miscanthus under different temperature regimes. Sustain. Chem. Process. 2015, 3. [CrossRef]

97. de la Hoz, A.; Diaz-Ortiz, A.; Moreno, A. Microwaves in organic synthesis. Thermal and non-thermal microwave effects. Chem. Soc. Rev. 2005, 34, 164-178. [CrossRef]

98. Kostas, E.T.; Beneroso, D.; Robinson, J.P. The application of microwave heating in bioenergy: A review on the microwave pre-treatment and upgrading technologies for biomass. Renew. Sustain. Energy Rev. 2017, 77, 12-27. [CrossRef]

99. Anita, S.H.; Fitria; Solihat, N.N.; Sari, F.P.; Risanto, L.; Fatriasari, W.; Hermiati, E. Optimization of Microwave-Assisted Oxalic Acid Pretreatment of Oil Palm Empty Fruit Bunch for Production of Fermentable Sugars. Waste Biomass Valorization 2019. [CrossRef]

100. Hu, J.; Jiang, B.; Wang, J.; Qiao, Y.; Zuo, T.; Sun, Y.; Jiang, X. Physicochemical characteristics and pyrolysis performance of corn stalk torrefied in aqueous ammonia by microwave heating. Bioresour. Technol. 2019, 274, 83-88. [CrossRef] [PubMed]

101. Kainthola, J.; Shariq, M.; Kalamdhad, A.S.; Goud, V.V. Enhanced methane potential of rice straw with microwave assisted pretreatment and its kinetic analysis. J. Environ. Manag. 2018, 232, 188-196. [CrossRef] [PubMed]

102. Zein, S.H.; Gyamera, B.A.; Skoulou, V.K. Nanocarbons from acid pretreated Waste Coffee Grounds using microwave radiation. Mater. Lett. 2017, 193, 46-49. [CrossRef]

103. Bussemaker, M.J.; Zhang, D. Effect of Ultrasound on Lignocellulosic Biomass as a Pretreatment for Biorefinery and Biofuel Applications. Ind. Eng. Chem. Res. 2013, 52, 3563-3580. [CrossRef]

104. Teran Hilares, R.; Ramos, L.; da Silva, S.S.; Dragone, G.; Mussatto, S.I.; Santos, J.C.D. Hydrodynamic cavitation as a strategy to enhance the efficiency of lignocellulosic biomass pretreatment. Crit. Rev. Biotechnol. 2018, 38, 483-493. [CrossRef]

105. Sasmal, S.; Goud, V.V.; Mohanty, K. Ultrasound Assisted Lime Pretreatment of Lignocellulosic Biomass toward Bioethanol Production. Energy Fuels 2012, 26, 3777-3784. [CrossRef]

106. Sindhu, R.; Binod, P.; Pandey, A. Biological pretreatment of lignocellulosic biomass-An overview. Bioresour. Technol. 2016, 199, 76-82. [CrossRef]

107. Wang, Z.; Qu, L.; Qian, J.; He, Z.; Yi, S. Effects of the ultrasound-assisted pretreatments using borax and sodium hydroxide on the physicochemical properties of Chinese fir. Ultrason. Sonochem. 2019, 50, $200-207$. [CrossRef]

108. Zheng, Y.; Zhao, J.; Xu, F.; Li, Y. Pretreatment of lignocellulosic biomass for enhanced biogas production. Prog. Energy Combust. Sci. 2014, 42, 35-53. [CrossRef] 
109. Bizzi, C.A.; Santos, D.; Sieben, T.C.; Motta, G.V.; Mello, P.A.; Flores, E.M.M. Furfural production from lignocellulosic biomass by ultrasound-assisted acid hydrolysis. Ultrason. Sonochem. 2019, 51, 332-339. [CrossRef] [PubMed]

110. Luo, J.; Fang, Z.; Smith, R.L. Ultrasound-enhanced conversion of biomass to biofuels. Prog. Energy Combust. Sci. 2014, 41, 56-93. [CrossRef]

111. Yu, X.; Bao, X.; Zhou, C.; Zhang, L.; Yagoub, A.E.A.; Yang, H.; Ma, H. Ultrasound-ionic liquid enhanced enzymatic and acid hydrolysis of biomass cellulose. Ultrason. Sonochem. 2018, 41, 410-418. [CrossRef] [PubMed]

112. Ravindran, R.; Jaiswal, A.K. A comprehensive review on pre-treatment strategy for lignocellulosic food industry waste: Challenges and opportunities. Bioresour. Technol. 2016, 199, 92-102. [CrossRef] [PubMed]

113. An, S.; Li, W.; Liu, Q.; Xia, Y.; Zhang, T.; Huang, F.; Lin, Q.; Chen, L. Combined dilute hydrochloric acid and alkaline wet oxidation pretreatment to improve sugar recovery of corn stover. Bioresour. Technol. 2019, 271, 283-288. [CrossRef] [PubMed]

114. McGinnis, G.D.; Wilson, W.W.; Mullen, C.E. Biomass Pretreatment with Water and High-Pressure Oxygen. The Wet-Oxidation Process. Ind. Eng. Chem. Prod. Res. Dev. 1983, 22, 352-357. [CrossRef]

115. Munir, M.T.; Mansouri, S.S.; Udugama, I.A.; Baroutian, S.; Gernaey, K.V.; Young, B.R. Resource recovery from organic solid waste using hydrothermal processing: Opportunities and challenges. Renew. Sustain. Energy Rev. 2018, 96, 64-75. [CrossRef]

116. Schmidt, A.S.; Thomsen, A.B. Optimization of wet oxidation pretreatment of wheat straw. Bioresour. Technol. 1998, 64, 139-151. [CrossRef]

117. Palonen, H.; Thomsen, A.B.; Tenkanen, M.; Schmidt, A.S.; Viikari, U. Evaluation of wet oxidation pretreatment for enzymatic hydrolysis of softwood. Appl. Biochem. Biotechnol. 2004, 117, 1-17. [CrossRef]

118. Li, C.; Knierim, B.; Manisseri, C.; Arora, R.; Scheller, H.V.; Auer, M.; Vogel, K.P.; Simmons, B.A.; Singh, S. Comparison of dilute acid and ionic liquid pretreatment of switchgrass: Biomass recalcitrance, delignification and enzymatic saccharification. Bioresour. Technol. 2010, 101, 4900-4906. [CrossRef] [PubMed]

119. Travaini, R.; Martin-Juarez, J.; Lorenzo-Hernando, A.; Bolado-Rodriguez, S. Ozonolysis: An advantageous pretreatment for lignocellulosic biomass revisited. Bioresour. Technol. 2016, 199, 2-12. [CrossRef] [PubMed]

120. Travaini, R.; Otero, M.D.; Coca, M.; Da-Silva, R.; Bolado, S. Sugarcane bagasse ozonolysis pretreatment: Effect on enzymatic digestibility and inhibitory compound formation. Bioresour. Technol. 2013, 133, 332-339. [CrossRef] [PubMed]

121. Den, W.; Sharma, V.K.; Lee, M.; Nadadur, G.; Varma, R.S. Lignocellulosic Biomass Transformations via Greener Oxidative Pretreatment Processes: Access to Energy and Value-Added Chemicals. Front. Chem. 2018, 6, 141. [CrossRef] [PubMed]

122. Alvira, P.; Tomas-Pejo, E.; Ballesteros, M.; Negro, M.J. Pretreatment technologies for an efficient bioethanol production process based on enzymatic hydrolysis: A review. Bioresour. Technol. 2010, 101, 4851-4861. [CrossRef] [PubMed]

123. Badiei, M.; Asim, N.; Jahim, J.M.; Sopian, K. Comparison of Chemical Pretreatment Methods for Cellulosic Biomass. APCBEE Procedia 2014, 9, 170-174. [CrossRef]

124. Taylor, M.J.; Jiang, L.; Reichert, J.; Papageorgiou, A.C.; Beaumont, S.K.; Wilson, K.; Lee, A.F.; Barth, J.V.; Kyriakou, G. Catalytic Hydrogenation and Hydrodeoxygenation of Furfural over Pt(111): A Model System for the Rational Design and Operation of Practical Biomass Conversion Catalysts. J. Phys. Chem. C 2017, 121, 8490-8497. [CrossRef] [PubMed]

125. Wang, P.; Chen, Y.M.; Wang, Y.; Lee, Y.Y.; Zong, W.; Taylor, S.; McDonald, T.; Wang, Y. Towards comprehensive lignocellulosic biomass utilization for bioenergy production: Efficient biobutanol production from acetic acid pretreated switchgrass with Clostridium saccharoperbutylacetonicum N1-4. Appl. Energy 2019, 236, 551-559. [CrossRef]

126. Sun, S.; Sun, S.; Cao, X.; Sun, R. The role of pretreatment in improving the enzymatic hydrolysis of lignocellulosic materials. Bioresour. Technol. 2016, 199, 49-58. [CrossRef] [PubMed]

127. Behera, S.; Arora, R.; Nandhagopal, N.; Kumar, S. Importance of chemical pretreatment for bioconversion of lignocellulosic biomass. Renew. Sustain. Energy Rev. 2014, 36, 91-106. [CrossRef]

128. Vanderghem, C.; Brostaux, Y.; Jacquet, N.; Blecker, C.; Paquot, M. Optimization of formic/acetic acid delignification of Miscanthus $\times$ giganteus for enzymatic hydrolysis using response surface methodology. Ind. Crops Prod. 2012, 35, 280-286. [CrossRef] 
129. Sahoo, D.; Ummalyma, S.B.; Okram, A.K.; Pandey, A.; Sankar, M.; Sukumaran, R.K. Effect of dilute acid pretreatment of wild rice grass (Zizania latifolia) from Loktak Lake for enzymatic hydrolysis. Bioresour. Technol. 2018, 253, 252-255. [CrossRef] [PubMed]

130. da Costa, R.M.; Pattathil, S.; Avci, U.; Lee, S.J.; Hazen, S.P.; Winters, A.; Hahn, M.G.; Bosch, M. A cell wall reference profile for Miscanthus bioenergy crops highlights compositional and structural variations associated with development and organ origin. New Phytol. 2017, 213, 1710-1725. [CrossRef] [PubMed]

131. Cai, J.; Zhang, L. Rapid dissolution of cellulose in $\mathrm{LiOH} /$ urea and $\mathrm{NaOH} /$ urea aqueous solutions. Macromol. Biosci. 2005, 5, 539-548. [CrossRef] [PubMed]

132. Kim, J.S.; Lee, Y.Y.; Kim, T.H. A review on alkaline pretreatment technology for bioconversion of lignocellulosic biomass. Bioresour. Technol. 2016, 199, 42-48. [CrossRef] [PubMed]

133. Hendriks, A.T.; Zeeman, G. Pretreatments to enhance the digestibility of lignocellulosic biomass. Bioresour. Technol. 2009, 100, 10-18. [CrossRef] [PubMed]

134. Shahabazuddin, M.; Sarat Chandra, T.; Meena, S.; Sukumaran, R.K.; Shetty, N.P.; Mudliar, S.N. Thermal assisted alkaline pretreatment of rice husk for enhanced biomass deconstruction and enzymatic saccharification: Physico-chemical and structural characterization. Bioresour. Technol. 2018, 263, 199-206. [CrossRef] [PubMed]

135. Sindhu, R.; Kuttiraja, M.; Binod, P.; Sukumaran, R.K.; Pandey, A. Physicochemical characterization of alkali pretreated sugarcane tops and optimization of enzymatic saccharification using response surface methodology. Renew. Energy 2014, 62, 362-368. [CrossRef]

136. Datta, S.; Holmes, B.; Park, J.I.; Chen, Z.; Dibble, D.C.; Hadi, M.; Blanch, H.W.; Simmons, B.A.; Sapra, R. Ionic liquid tolerant hyperthermophilic cellulases for biomass pretreatment and hydrolysis. Green Chem. 2010, 12, 338-345. [CrossRef]

137. Weerachanchai, P.; Lee, J.M. Recyclability of an ionic liquid for biomass pretreatment. Bioresour. Technol. 2014, 169, 336-343. [CrossRef]

138. Yuan, X.; Singh, S.; Simmons, B.A.; Cheng, G. Biomass Pretreatment Using Dilute Aqueous Ionic Liquid (IL) Solutions with Dynamically Varying IL Concentration and Its Impact on IL Recycling. ACS Sustain. Chem. Eng. 2017, 5, 4408-4413. [CrossRef]

139. Doherty, T.V.; Mora-Pale, M.; Foley, S.E.; Linhardt, R.J.; Dordick, J.S. Ionic liquid solvent properties as predictors of lignocellulose pretreatment efficacy. Green Chem. 2010, 12, 1967-1975. [CrossRef]

140. Samayam, I.P.; Schall, C.A. Saccharification of ionic liquid pretreated biomass with commercial enzyme mixtures. Bioresour. Technol. 2010, 101, 3561-3566. [CrossRef]

141. Zhu, S.; Wu, Y.; Chen, Q.; Yu, Z.; Wang, C.; Jin, S.; Ding, Y.; Wu, G. Dissolution of cellulose with ionic liquids and its application: A mini-review. Green Chem. 2006, 8, 325-327. [CrossRef]

142. Yu, C.; Thy, P.; Wang, L.; Anderson, S.N.; VanderGheynst, J.S.; Upadhyaya, S.K.; Jenkins, B.M. Influence of leaching pretreatment on fuel properties of biomass. Fuel Process. Technol. 2014, 128, 43-53. [CrossRef]

143. Gong, S.H.; Im, H.S.; Um, M.; Lee, H.W.; Lee, J.W. Enhancement of waste biomass fuel properties by sequential leaching and wet torrefaction. Fuel 2019, 239, 693-700. [CrossRef]

144. Ravichandran, P.; Corscadden, K. Comparison of gaseous and particle emissions produced from leached and un-leached agricultural biomass briquettes. Fuel Process. Technol. 2014, 128, 359-366. [CrossRef]

145. Arvelakis, S.; Vourliotis, P.; Kakaras, E.; Koukios, E.G. Effect of leaching on the ash behavior of wheat straw and olive residue during fluidized bed combustion. Biomass Bioenergy 2001, 20, 459-470. [CrossRef]

146. Bridgwater, A.V. Upgrading biomass fast pyrolysis liquids. Environ. Prog. Sustain. Energy 2012, 31, 261-268. [CrossRef]

147. Mihalcik, D.J.; Mullen, C.A.; Boateng, A.A. Screening acidic zeolites for catalytic fast pyrolysis of biomass and its components. J. Anal. Appl. Pyrolysis 2011, 92, 224-232. [CrossRef]

148. Fahmi, R.; Bridgwater, A.V.; Darvell, L.I.; Jones, J.M.; Yates, N.; Thain, S.; Donnison, I.S. The effect of alkali metals on combustion and pyrolysis of Lolium and Festuca grasses, switchgrass and willow. Fuel 2007, 86, 1560-1569. [CrossRef]

149. Mahadevan, R.; Adhikari, S.; Shakya, R.; Wang, K.; Dayton, D.; Lehrich, M.; Taylor, S.E. Effect of Alkali and Alkaline Earth Metals on in-Situ Catalytic Fast Pyrolysis of Lignocellulosic Biomass: A Microreactor Study. Energy Fuels 2016, 30, 3045-3056. [CrossRef] 
150. Skoulou, V.; Kantarelis, E.; Arvelakis, S.; Yang, W.; Zabaniotou, A. Effect of biomass leaching on H2 production, ash and tar behavior during high temperature steam gasification (HTSG) process. Int. J. Hydrogen Energy 2009, 34, 5666-5673. [CrossRef]

151. Cen, K.; Zhang, J.; Ma, Z.; Chenc, D.; Zhou, J.; Ma, H. Investigation of the relevance between biomass pyrolysis polygenerationand washing pretreatment under different severities Water, dilute acidsolution and aqueous phase bio-oil. Bioresour. Technol. 2019, 278, 26-33. [CrossRef] [PubMed]

152. Wu, H.; Yip, K.; Kong, Z.; Li, C.-Z.; Liu, D.; Yu, Y.; Gao, X. Removal and Recycling of Inherent Inorganic Nutrient Species in Mallee Biomass and Derived Biochars by Water Leaching. Ind. Eng. Chem. Res. 2011, 50, 12143-12151. [CrossRef]

153. Tonn, B.; Thumm, U.; Lewandowski, I.; Claupein, W. Leaching of biomass from semi-natural grasslands-Effects on chemical composition and ash high-temperature behaviour. Biomass Bioenergy 2012, 36, 390-403. [CrossRef]

154. Dayton, D.C.; Jenkins, B.M.; Turn, S.Q.; Bakker, R.R.; Williams, R.B.; Belle-Oudry, D.; Hill, L.M. Release of inorganic constituents from leached biomass during thermal conversion. Energy Fuels 1999, 13, 860-870. [CrossRef]

155. Oudenhoven, S.R.G.; van der Ham, A.G.J.; van den Berg, H.; Westerhof, R.J.M.; Kersten, S.R.A. Using pyrolytic acid leaching as a pretreatment step in a biomass fast pyrolysis plant: Process design and economic evaluation. Biomass Bioenergy 2016, 95, 388-404. [CrossRef]

156. Rodriguez-Machin, L.; Arteaga-Perez, L.E.; Pala, M.; Herregods-Van de Pontseele, K.; Perez-Bermudez, R.A.; Feys, J.; Prins, W.; Ronsse, F. Influence of citric acid leaching on the yield and quality of pyrolytic bio-oils from sugarcane residues. J. Anal. Appl. Pyrolysis 2019, 137, 43-53. [CrossRef]

157. Southard, M.Z.; Green, D.W. Perry's Chemical Engineers' Handbook, 9th ed.; McGraw-Hill Education: New York, NY, USA, 2018.

158. Ma, Q.; Han, L.; Huang, G. Potential of water-washing of rape straw on thermal propertiesand interactions during co-combustion with bituminous coal. Bioresour. Technol. 2017, 234, 53-60. [CrossRef]

159. Deng, L.; Zhang, T.; Che, D. Effect of water washing on fuel properties, pyrolysis and combustion characteristics, and ash fusibility of biomass. Fuel Process. Technol. 2013, 106, 712-720. [CrossRef]

160. Jensen, P.A.; Sander, B.; Dam-Johansen, K. Removal of $\mathrm{K}$ and $\mathrm{Cl}$ by leaching of straw char. Biomass Bioenergy 2001, 20, 447-457. [CrossRef]

161. Davidsson, K.O.; Korsgren, J.G.; Pettersson, J.B.C.; Jaglid, U. The effects of fuel washing techniques on alkali release from biomass. Fuel 2002, 81, 137-142. [CrossRef]

162. Turn, S.Q.; Kinoshita, C.M.; Ishimura, D.M. Removal of inorganic constituents of biomass feedstocks by mechanical dewatering and leaching. Biomass Bioenergy 1997, 12, 241-252. [CrossRef]

163. Kumar, P.; Barrett, D.M.; Delwiche, M.J.; Stroeve, P. Pulsed Electric Field Pretreatment of Switchgrass and Wood Chip Species for Biofuel Production. Ind. Eng. Chem. Res. 2011, 50, 10996-11001. [CrossRef]

164. Hassan, S.S.; Williams, G.A.; Jaiswal, A.K. Emerging technologies for the pretreatment of lignocellulosic biomass. Bioresour. Technol. 2018, 262, 310-318. [CrossRef]

165. Hu, Y.; Gong, M.; Feng, S.; Xu, C.; Bassi, A. A review of recent developments of pre-treatment technologies and hydrothermal liquefaction of microalgae for bio-crude oil production. Renew. Sustain. Energy Rev. 2019, 101, 476-492. [CrossRef]

166. Taiwo, K.A.; Angersbach, A.; Ade-Omowaye, B.I.O.; Knorr, D. Effects of pretreatments on the diffusion kinetics and some quality parameters of osmotically dehydrated apple slices. J. Agric. Food Chem. 2001, 49, 2804-2811. [CrossRef]

167. Duarte, C.L.; Ribeiro, M.A.; Oikawa, H.; Mori, M.N.; Napolitano, C.M.; Galvão, C.A. Electron beam combined with hydrothermal treatment for enhancing the enzymatic convertibility of sugarcane bagasse. Radiat. Phys. Chem. 2012, 81, 1008-1011. [CrossRef]

168. Leskinen, T.; Kelley, S.S.; Argyropoulos, D.S. E-beam irradiation \& steam explosion as biomass pretreatment, and the complex role of lignin in substrate recalcitrance. Biomass Bioenergy 2017, 103, 21-28. [CrossRef]

169. Khan, A.W.; Labrie, J.P.; Mckeown, J. Effect of Electron-Beam Irradiation Pretreatment on the Enzymatic-Hydrolysis of Softwood. Biotechnol. Bioeng. 1986, 28, 1449-1453. [CrossRef] [PubMed]

170. Singh, R.; Krishna, B.B.; Kumar, J.; Bhaskar, T. Opportunities for utilization of non-conventional energy sources for biomass pretreatment. Bioresour. Technol. 2016, 199, 398-407. [CrossRef] [PubMed] 
171. Taherzadeh, M.J.; Karimi, K. Pretreatment of lignocellulosic wastes to improve ethanol and biogas production: A review. Int. J. Mol. Sci. 2008, 9, 1621-1651. [CrossRef] [PubMed]

172. Bak, J.S. Electron beam irradiation enhances the digestibility and fermentation yield of water-soaked lignocellulosic biomass. Biotechnol. Rep. 2014, 4, 30-33. [CrossRef] [PubMed]

173. Xin, L.Z.; Kumakura, M. Effect of Radiation Pretreatment on Enzymatic-Hydrolysis of Rice Straw with Low Concentrations of Alkali Solution. Bioresour. Technol. 1993, 43, 13-17. [CrossRef]

174. Bak, J.S.; Ko, J.K.; Han, Y.H.; Lee, B.C.; Choi, I.G.; Kim, K.H. Improved enzymatic hydrolysis yield of rice straw using electron beam irradiation pretreatment. Bioresour. Technol. 2009, 100, 1285-1290. [CrossRef]

175. Yang, G.; Wang, J. Pretreatment of grass waste using combined ionizing radiation-acid treatment for enhancing fermentative hydrogen production. Bioresour. Technol. 2018, 255, 7-15. [CrossRef]

176. Khan, F. Characterization of methyl methacrylate grafting onto preirradiated biodegradable lignocellulose fiber by gamma-radiation. Macromol. Biosci. 2005, 5, 78-89. [CrossRef]

177. Yin, Y.; Wang, J. Enhancement of enzymatic hydrolysis of wheat straw by gamma irradiation-alkaline pretreatment. Radiat. Phys. Chem. 2016, 123, 63-67. [CrossRef]

C 2019 by the authors. Licensee MDPI, Basel, Switzerland. This article is an open access article distributed under the terms and conditions of the Creative Commons Attribution (CC BY) license (http://creativecommons.org/licenses/by/4.0/). 